Article

\title{
A Single-Stage LED Streetlight Driver with Soft-Switching and Interleaved PFC Features
}

\author{
Chun-An Cheng, Chien-Hsuan Chang ${ }^{\circledR}$, Hung-Liang Cheng ${ }^{\circledR}$, En-Chih Chang *, \\ Tsung-Yuan Chung and Man-Tang Chang \\ Department of Electrical Engineering, I-Shou University, Dashu District, Kaohsiung City 84001, Taiwan \\ * Correspondence: enchihchang@isu.edu.tw; Tel.: +886-7-657-7711 (ext. 6642)
}

Received: 10 July 2019; Accepted: 15 August 2019; Published: 18 August 2019

\begin{abstract}
This paper presents a single-stage driver with soft-switching and interleaved power-factor correction (PFC) features suitable for light-emitting diode (LED) energy-saving streetlight applications. The proposed LED streetlight driver integrates an interleaved buck-boost PFC converter with coupled inductors and a half-bridge LLC resonant converter into a single-stage power-conversion circuit with reduced voltage stress on the DC-linked capacitor and power switches, and it is suitable for operating at high utility-line voltages. Furthermore, coupled inductors in the interleaved buck-boost PFC converter are operated in discontinuous-conduction mode (DCM) for accomplishing PFC, and the half-bridge LLC resonant converter features zero-voltage switching (ZVS) to reduce switching losses of power switches, and zero-current switching (ZCS) to decrease conduction losses of power diodes. Operational modes and design considerations for the proposed LED streetlight driver are introduced. Finally, a $144 \mathrm{~W}$ (36V/4A)-rated LED prototype driver is successfully developed and implemented for supplying a streetlight module and operating with a utility-line input voltage of 220 V. High power factor, low output-voltage ripple factor, low output-current ripple factor, and high efficiency are achieved in the proposed LED streetlight driver.
\end{abstract}

Keywords: converter; LED; power-factor correction (PFC); soft-switching; streetlight driver

\section{Introduction}

With recent developments in green lighting and energy saving around the world, light-emitting diodes (LEDs) are characterized by their small size, long life, high brightness and environmental friendliness [1-3]. As a result, LEDs have begun to play important roles as new solid-state light sources for indoor and outdoor energy-saving applications in our daily lives [4-11].

Streetlights that illuminate the road are designed to provide a safe night-time environment for cars, motorcycles, cyclists and pedestrians. The traditional source of illumination for streetlight applications is high-pressure mercury lamps, because of their low installation cost. However, high-pressure mercury lamps consume more energy and save less electricity. In addition, the discharge tubes of these lamps contain mercury vapor, which is harmful and can cause pollution to our environment when the lamp is exhausted. Therefore, LED streetlights with energy-saving features have begun replacing traditional high-pressure mercury street lamps [12,13]. Traditional two-stage drivers for LED streetlight applications include AC-DC converters with power-factor correction (PFC) and DC-DC converters that provide rated voltage and current to the LED streetlight [14,15]. However, the circuit is not efficient, and requires more power switches and components in a conventional two-stage streetlight driver. The literature presents some single-stage streetlight drivers that integrate an AC-DC converter with a DC-DC converter [16-20]. Figure 1 shows an existing single-stage LED streetlight driver, which combines an interleaved boost converter with a half-bridge-type LLC resonant converter into a 
single-stage power converter for supplying the LED street-lighting module at a utility-line voltage of 110V [16]. The LED streetlight driver comprises a low-pass filter, a bridge rectifier $\left(D_{r 1}, D_{r 2}, D_{r 3}\right.$ and $\left.D_{r 4}\right)$, two capacitors $\left(C_{i n 1}\right.$ and $\left.C_{i n 2}\right)$, two diodes $\left(D_{B 1}\right.$ and $\left.D_{B 2}\right)$, two inductors $\left(L_{1}\right.$ and $\left.L_{2}\right)$, two power switches $\left(S_{1}\right.$ and $\left.S_{2}\right)$, a DC-linked capacitor $C_{D C}$, a resonant capacitor $C_{r}$ and an inductor $L_{r}$, a center-tapped transformer $T$ with two output windings, two diodes $\left(D_{1}\right.$ and $\left.D_{2}\right)$, a capacitor $C_{o}$ and the LED streetlight module. This kind of single-stage streetlight driver based on interleaved boost conversion is suitable for operating at utility-line voltages from 100 120 V in American and Asian countries, but will tolerate high voltage levels on the DC-linked capacitor $C_{D C}$ when it operates at higher utility-line voltages due to boost-type power conversion, such as the 220 240 V in European countries. In addition, the voltage stresses of the power switches in this version will increase. Another existing single-stage LED streetlight driver, which integrates an interleaved boost PFC converter with a half-bridge-type series-resonant converter cascaded with a bridge rectifier for supplying the LED street-lighting module at a utility-line voltage of $220 \mathrm{~V}$ was proposed in [20], and high voltage stresses of power switches occurred in this version due to the boost-type power conversion; therefore, the level of DC-bus voltage is increased, and two DC-linked capacitors are required.

To meet these challenges, this paper proposes and implements a single-stage LED streetlight driver based on interleaved buck-boost conversion with PFC and soft-switching functions, which is suitable for operating at high utility-line voltages along with reduced voltage levels on the DC-linked capacitor and decreased voltage stresses on the power switches due to a buck-boost-type power conversion. This paper introduces the description and analysis of the operating modes, the design considerations of the key circuit components in the proposed LED streetlight driver, and experimental results obtained from the $144 \mathrm{~W}(36 \mathrm{~V} / 4 \mathrm{~A})$-rated prototype circuit are included.

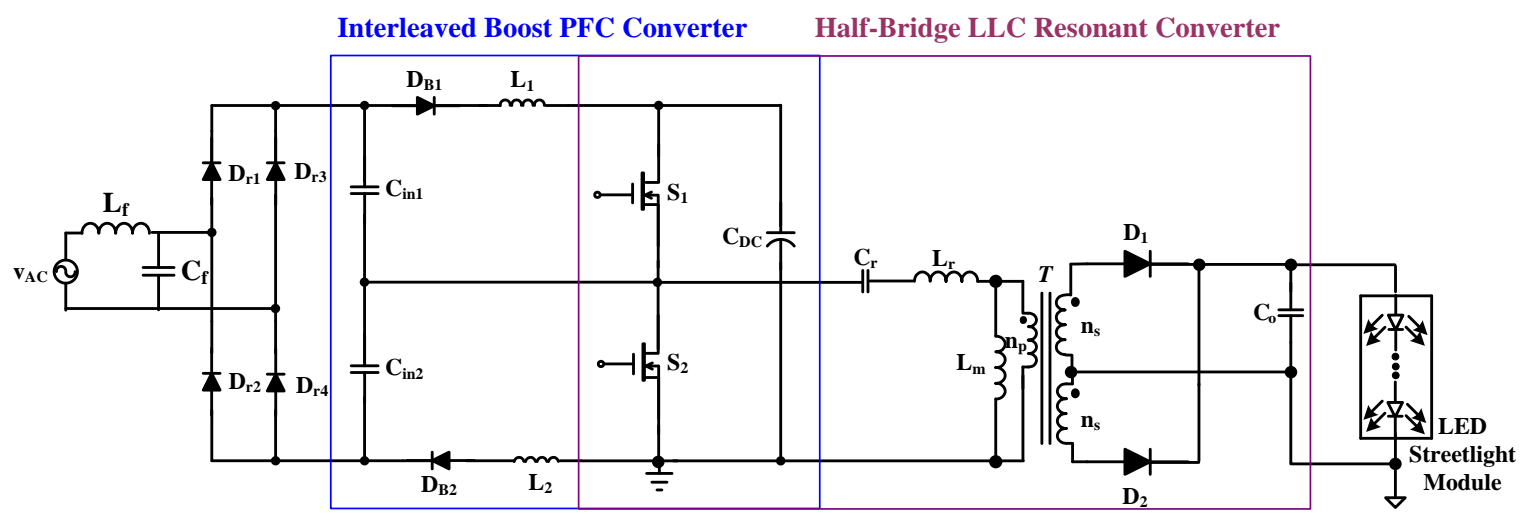

Figure 1. The existing single-stage LED streetlight driver.

\section{Circuit Derivation and Analysis of the Proposed Single-Stage LED Streetlight Driver}

Figure 2a shows the original two-stage LED streetlight driver, which consists of buck-boost PFC converter \#1 and buck-boost PFC converter \#2 with interleaved operation in series connection with a half-bridge LLC resonant converter. In addition, the two coupled inductors are employed instead of single-winding inductors in order to accomplish buck-boost conversion. Figure $2 \mathrm{~b}$ shows the presented LED streetlight driver with soft-switching and interleaved PFC feature, which integrates an interleaved buck-boost PFC converter with a half-bridge LLC resonant converter into single-stage power conversion and includes a low-pass filter $\left(L_{f}\right.$ and $\left.C_{f}\right)$, a bridge rectifier $\left(D_{r 1}, D_{r 2}, D_{r 3}\right.$ and $\left.D_{r 4}\right)$, two capacitors $\left(C_{i n 1}\right.$ and $\left.C_{i n 2}\right)$, two coupled inductors $\left(L_{B 1}\right.$ and $L_{B 2} ; L_{B 3}$ and $\left.L_{B 4}\right)$, four diodes $\left(D_{B 1}, D_{B 2}\right.$, $D_{B 3}$, and $\left.D_{B 4}\right)$, two power switches $\left(S_{1}\right.$ and $\left.S_{2}\right)$, a DC-bus capacitor $\left(C_{D C}\right)$, a resonant capacitor $\left(C_{r}\right)$, a resonant inductor $\left(L_{r}\right)$, a center-tapped transformer $T$ with a magnetizing inductor $L_{m}$ and two output windings, two output diodes $D_{1}$ and $D_{2}$, an output capacitor $\left(C_{o}\right)$ and the LED streetlight module. In addition, the diodes $D_{B 2}$ and $D_{B 3}$ are used to prevent current from entering the inductors $L_{B 2}$ and $L_{B 3}$ from the $A C$ mains voltage sources. Furthermore, diodes $D_{B 1}$ and $D_{B 4}$ are capable of preventing 
the inductor currents from returning to the input capacitors $C_{i n 1}$ and $C_{i n 2}$. Since the voltage on the capacitor $C_{i n 1}$ or $C_{i n 2}$ is half of the utility-line voltage, the DC-bus voltage and the peak current of each coupled inductor will also be half. Due to the reduced DC-bus voltage, power switches with decreased voltage-stress can be utilized in the proposed LED streetlight driver, which is advantageous for high utility-line voltage applications.

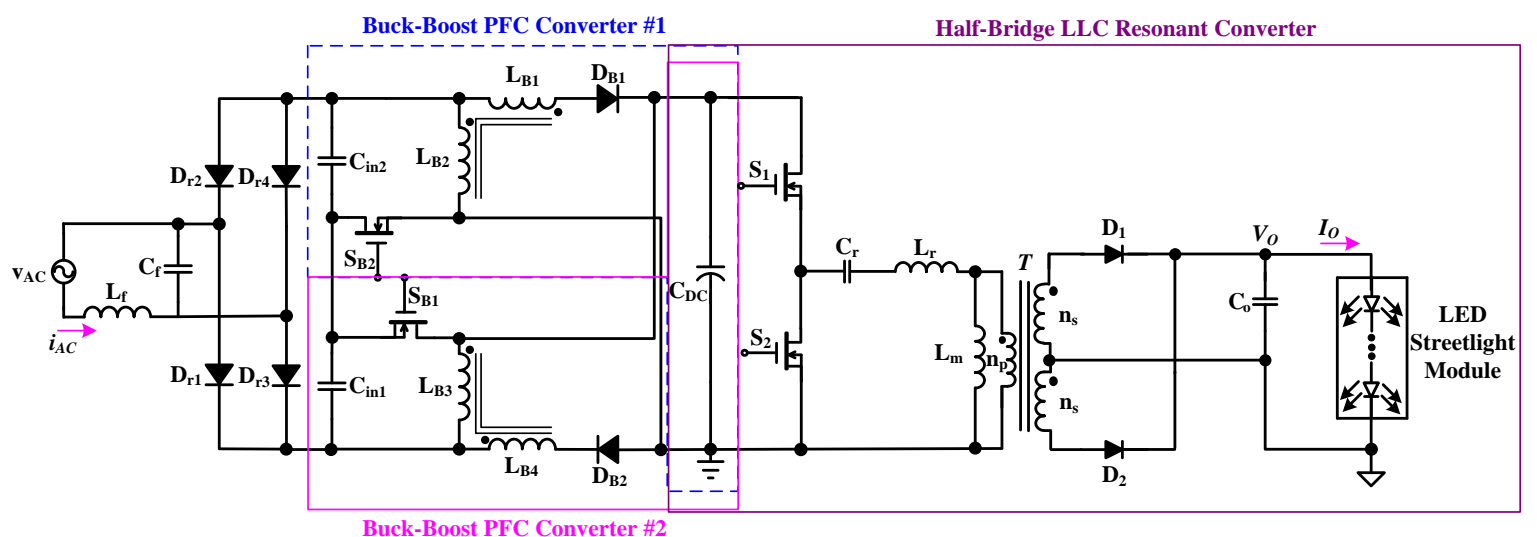

(a)

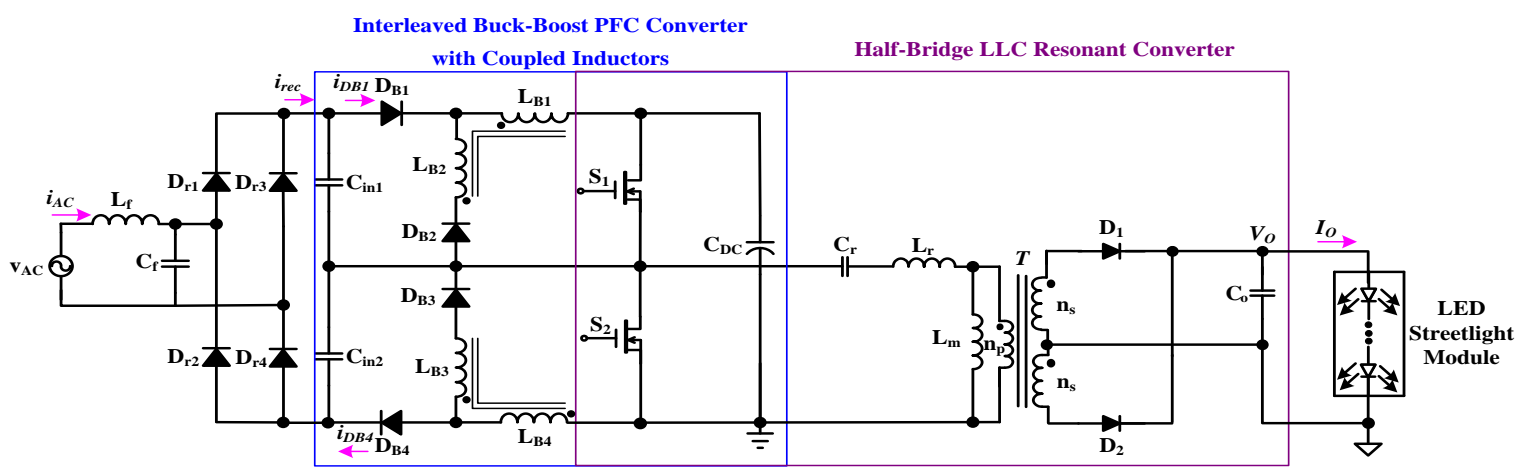

(b)

Figure 2. (a) Original two-stage LED streetlight driver; (b) the presented single-stage LED streetlight driver with coupled inductors and interleaved PFC feature.

Figure 3 shows a simplified circuit of the proposed single-stage LED streetlight driver when analyzing its operating modes. To describe the operation of the proposed LED streetlight driver, the following assumptions are made.

(a) Since the switching frequency of the power switches is much higher than the utility-line frequency, the sinusoidal utility-line voltage can be considered to be a constant value in each high-frequency switching period.

(b) The voltage sources $V_{R E C 1}$ and $V_{R E C 2}$ of capacitors $C_{i n 1}$ and $C_{i n 2}$, respectively, represent the rectified input utility-line voltages.

(c) The power switches $S_{1}$ and $S_{2}$ operate complementarily, and their intrinsic body diode and drain-source capacitance are taken into consideration.

(d) The turn-on voltage drops of diodes $\left(D_{B 1}, D_{B 2}, D_{B 3}, D_{B 4}, D_{1}\right.$ and $\left.D_{2}\right)$ are omitted.

(e) To naturally obtain PFC, the coupled inductors $\left(L_{B 1}\right.$ and $L_{B 2} ; L_{B 3}$ and $\left.L_{B 4}\right)$ are designed to operate in discontinuous-conduction mode (DCM). 


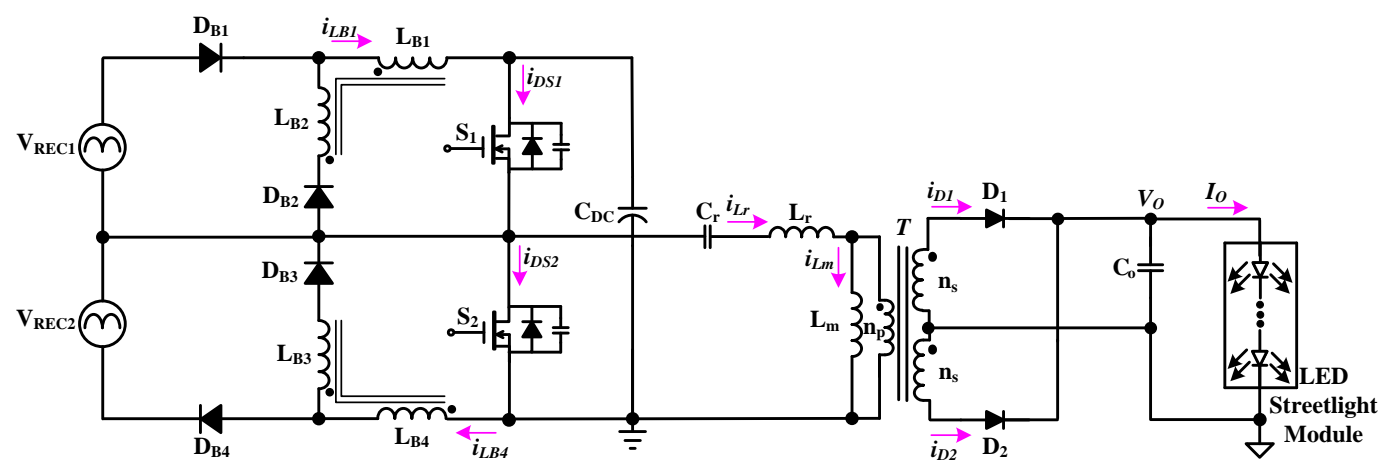

Figure 3. The simplified circuit of the presented single-stage LED driver for streetlight applications.

The operational modes and key waveforms of the LED streetlight driver proposed in this paper are shown in Figures 4 and 5, respectively, and the analysis of the operation is described in detail below.

Mode $1\left(t_{0} \leq t<t_{1}\right.$; in Figure 4a): When the switch voltage $v_{D S 1}$ decreases to zero and the body diode of switch $S_{1}$ is forward-biased at time interval $t_{0}$, this mode begins and the power switch $S_{1}$ turns on with zero-voltage switching (ZVS). The voltage source $V_{R E C 1}$ charges the coupled inductor $L_{B 1}$ through diode $D_{B 1}$ and switch $S_{1}$. The inductor current $i_{L B 1}$ increases linearly from zero and can be given by:

$$
i_{L B 1}(t)=\frac{\left|\sqrt{2} v_{A C-r m s} \sin \left(2 \pi f_{A C} t\right)\right|}{2 L_{B 1}}\left(t-t_{0}\right)
$$

where $v_{A C \text {-rms }}$ represents the rms value of input utility-line voltage, and $f_{A C}$ represents the utility-line frequency.

The resonant inductor $L_{r}$ and magnetizing inductor $L_{m}$ provide energy to the resonant capacitor $C_{r}$ and to DC-linked capacitor $C_{D C}$ through the body diode of switch $S_{1}$, and to the output capacitor $C_{o}$ and the LED streetlight module through transformer $T$ and output diode $D_{1}$. The diode $D_{B 3}$ is forward-biased, and the coupled inductors $L_{B 3}$ and $L_{B 4}$ provide energy to the drain-source capacitor of switch $S_{2}$ through diode $D_{B 3}$. This mode ends when the resonant inductor current $i_{L r}$ is zero at time $t_{1}$.

Mode $2\left(t_{1} \leq t<t_{2}\right.$; in Figure $\left.4 \mathrm{~b}\right)$ : This mode is activated when the resonant inductor current $i_{L r}$ reaches zero at $t_{1}$. The voltage source $V_{R E C 1}$ continues charging the coupled inductor $L_{B 1}$ through diode $D_{B 1}$ and switch $S_{1}$.

The capacitors $C_{D C}$, the magnetizing inductor $L_{m}$ and the coupled inductors $L_{B 3}$ and $L_{B 4}$ provide energy to the drain-source capacitor of switch $S_{2}$, the resonant inductor $L_{r}$ and the resonant capacitor $C_{r}$ through $D_{B 3}$, and to the output capacitor $C_{o}$ and the LED streetlight module through transformer $T$ and output diode $D_{1}$. When the magnetizing inductor current $i_{L m}$ and inductor current $i_{L B 4}$ become zero at $t_{2}$, this mode finishes.

Mode 3 ( $t_{2} \leq t<t_{3}$; in Figure $\left.4 \mathrm{c}\right)$ : At $t_{2}$, the voltage source $V_{R E C 1}$ continues charging the coupled inductor $L_{B 1}$ through $D_{B 1}$ and $S_{1}$. The capacitors $C_{D C}$ provides energy to the resonant inductor $L_{r}$, the resonant capacitor $C_{r}$, and the magnetizing inductor $L_{m}$ through $S_{1}$, and to the output capacitor $C_{o}$ and the LED streetlight module through transformer $T$ and output diode $D_{1}$. This mode ends when the diode current $i_{D 1}$ becomes zero at $t_{3}$.

Mode $4\left(t_{3} \leq t<t_{4}\right.$; in Figure $\left.4 \mathrm{~d}\right)$ : This mode activates when $i_{D 1}$ is zero at $t_{3}$. The voltage source $V_{R E C 1}$ continues charging the coupled inductor $L_{B 1}$ through $D_{B 1}$ and $S_{1}$. The capacitor $C_{D C}$ continues providing energy to the inductors $L_{r}$ and $L_{m}$ and to $C_{r}$ through $S_{1}$. The output capacitor $C_{o}$ provides energy to the LED streetlight module. The coupled-inductor current $i_{L B 1}$ reaches its peak value at $t_{4}$ which is denoted as $i_{L B 1-p k}(t)$, and is given by:

$$
i_{L B 1-p k}(t)=\frac{\left|\sqrt{2} v_{A C-r m s} \sin \left(2 \pi f_{A C} t\right)\right|}{2 L_{B 1}} D T_{S}
$$


where $T_{S}$ and $D$ are the period and the duty cycle of the power switch, respectively.

When switch $S_{1}$ turns off at $t_{4}$, this mode finishes.

Mode $5\left(t_{4} \leq t<t_{5}\right.$; in Figure 4e): This mode begins when $S_{1}$ is off and $i_{L B 1}$ is at its maximum level at $t_{4}$. The diode $D_{B 2}$ is forward-biased and coupled inductors $L_{B 1}$ and $L_{B 2}$ provide energy to the drain-source capacitor of $S_{1}$ through $D_{B 2}$. The coupled-inductor current $i_{L B 1}$ linearly decreases, and it can be given by:

$$
i_{L B 1}(t)=\frac{V_{D C}}{4 L_{B 1}}\left(t-t_{4}\right)
$$

where $V_{D C}$ represents the voltage of the DC-bus capacitor.

The capacitor $C_{D C}$ and the drain-source capacitor of $S_{2}$, provide energy to inductors $L_{r}$ and $L_{m}$ and to $C_{r}$. The output capacitor $C_{o}$ continues providing energy to the LED streetlight module. At time interval $t_{5}$, the voltage $v_{D S 2}$ of power switch $S_{2}$ is decreased to zero; then this mode ends.

Mode $6\left(t_{5} \leq t<t_{6}\right.$; in Figure $\left.4 \mathrm{f}\right)$ : When the switch voltage $v_{D S 2}$ is decreased to zero and the body diode of switch $S_{2}$ is forward-biased at $t_{5}$, this mode activates and the power switch $S_{2}$ turns on with ZVS feature. The voltage source $V_{R E C 2}$ provides energy to coupled inductor $L_{B 4}$ through diode $D_{B 4}$ and switch $S_{2}$, and the inductor current $i_{L B 4}$ increases linearly from zero. The coupled inductors $L_{B 1}$ and $L_{B 2}$ continue providing energy to the drain-source capacitor of $S_{1}$ through $D_{B 2}$, and the inductor current $i_{L B 1}$ continues linearly decreasing. The capacitor $C_{D C}$ continues providing energy to inductors $L_{r}$ and $L_{m}$ and to the resonant capacitor $C_{r}$ through the body diode of $S_{2}$. The output capacitor $C_{o}$ continues providing energy to the LED streetlight module. This mode finishes when the magnetizing inductor current $i_{L m}$ reaches its peak value at $t_{6}$.

Mode 7 ( $t_{6} \leq t<t_{7}$; in Figure $4 \mathrm{~g}$ ): This mode begins when the magnetizing inductor current $i_{L m}$ is at its maximum level at $t_{6}$. The voltage source $V_{R E C 2}$ continues providing energy to coupled inductor $L_{B 4}$ through diode $D_{B 4}$ and switch $S_{2}$, and $i_{L B 4}$ continues linearly increasing. The coupled inductors $L_{B 1}$ and $L_{B 2}$ continue providing energy to the drain-source capacitor of $S_{1}$ through $D_{B 2}$, and $i_{L B 1}$ continues linearly decreasing. The DC-linked capacitor $C_{D C}$ provides energy to the drain-source capacitor of $S_{1}$ through $S_{2}$. The resonant inductor $L_{r}$ provides energy to resonant capacitor $C_{r}$ through switch $S_{2}$. The magnetizing inductor $L_{m}$ provides energy to the output capacitor $C_{o}$ and the LED streetlight module through transformer $T$ and diode $D_{2}$. This mode ends when the inductor current $i_{L B 1}$ is decreased to zero at $t_{7}$.

Mode $8\left(t_{7} \leq t<t_{8}\right.$; in Figure $\left.4 \mathrm{~h}\right)$ : This mode activates when the current $i_{L B 1}$ is zero at $t_{7}$. The voltage source $V_{R E C 2}$ continues providing energy to coupled inductor $L_{B 4}$ through diode $D_{B 4}$ and switch $S_{2}$. The coupled inductors $L_{B 1}$ and $L_{B 2}$ continue providing energy to the drain-source capacitor of $S_{1}$ through $D_{B 2}$. The DC-linked capacitor $C_{D C}$ continues providing energy to the drain-source capacitor of $S_{1}$ through $S_{2}$. The resonant inductor $L_{r}$ and the magnetizing inductor $L_{m}$ provide energy to resonant capacitor $C_{r}$ through switch $S_{2}$ and to the output capacitor $C_{o}$ along with the LED streetlight module through transformer $T$ and diode $D_{2}$. This mode finishes when the magnetizing inductor current $i_{L m}$ is decreased to zero at $t_{8}$.

Mode $9\left(t_{8} \leq t<t_{9}\right.$; in Figure 4i): This mode begins when the magnetizing inductor current $i_{L m}$ is zero at $t_{8}$. The voltage source $V_{R E C 2}$ continues providing energy to coupled inductor $L_{B 4}$ through diode $D_{B 4}$ and switch $S_{2}$, and $i_{L B 4}$ continues linearly increasing. The DC-linked capacitor $C_{D C}$ continues providing energy to the drain-source capacitor of $S_{1}$ through $S_{2}$. The inductors $L_{r}$ and $L_{m}$ continue providing energy to the capacitor $C_{r}$ through switch $S_{2}$, and to the output capacitor $C_{o}$ along with the LED streetlight module through transformer $T$ and diode $D_{2}$. When the diode current $i_{D 2}$ decreases to zero, this mode ends.

Mode $10\left(t_{9} \leq t<t_{10}\right.$; in Figure 4j): This mode activates when the current $i_{D 2}$ is zero at $t_{9}$. The voltage source $V_{R E C 2}$ continues providing energy to the coupled inductor $L_{B 4}$ through $D_{B 4}$ and $S_{2}$, and $i_{L B 4}$ continues increasing linearly. The DC-linked capacitor $C_{D C}$ continues providing energy to the drain-source capacitor of $S_{1}$ through $S_{2}$. The inductors $L_{r}$ and $L_{m}$ continue providing energy to the 
capacitor $C_{r}$ through switch $S_{2}$. The output capacitor $C_{o}$ supplies energy to the LED streetlight module. When $S_{2}$ turns off and $i_{L B 4}$ reaches its peak value at $t_{10}$, this mode finishes.

Mode 11 ( $t_{10} \leq t<t_{11}$; in Figure 4k): This mode begins when switch $S_{2}$ is turned off and $i_{L B 4}$ is at its maximum level at $t_{10}$. The coupled inductors $L_{B 3}$ and $L_{B 4}$ provide energy to the drain-source capacitor of $S_{2}$ through $D_{B 3}$, and the inductor current $i_{L B}$ linearly decreases. The drain-source capacitor of $S_{1}$ and the inductors $L_{r}$ and $L_{m}$ supply energy to capacitors $C_{r}$ and $C_{D C}$. The output capacitor $C_{o}$ still provides energy to the LED streetlight module. When the switch voltage $v_{D S 1}$ decreases to zero at $t_{11}$, this mode ends, and Mode 1 begins again for the next switching period.

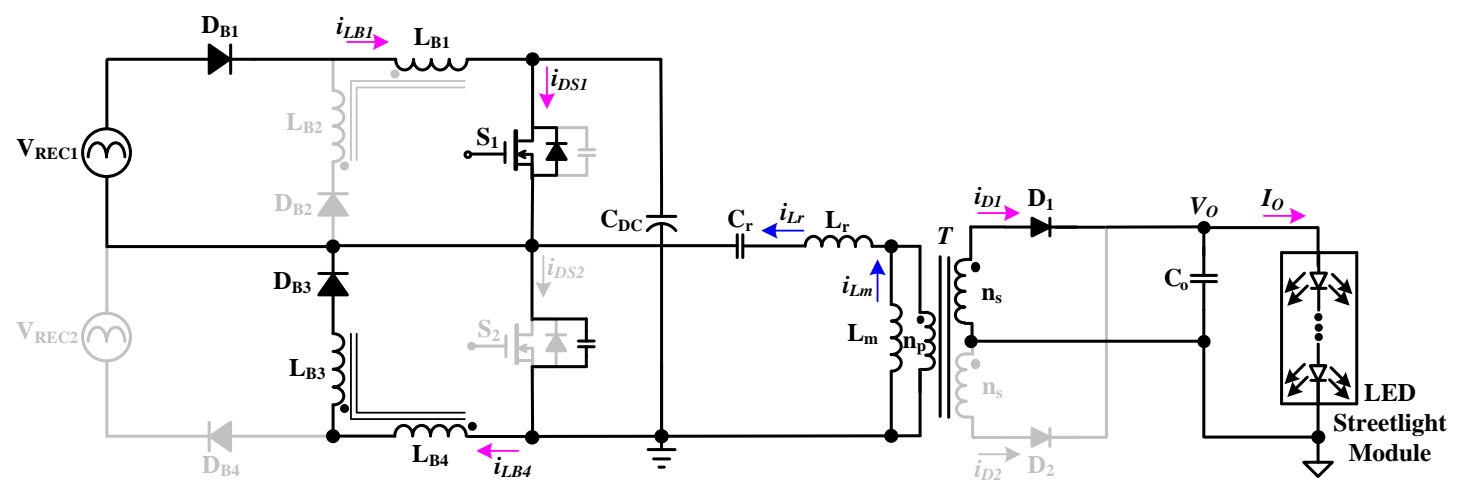

(a) Mode $1\left(t_{0} \leq t<t_{1}\right)$.

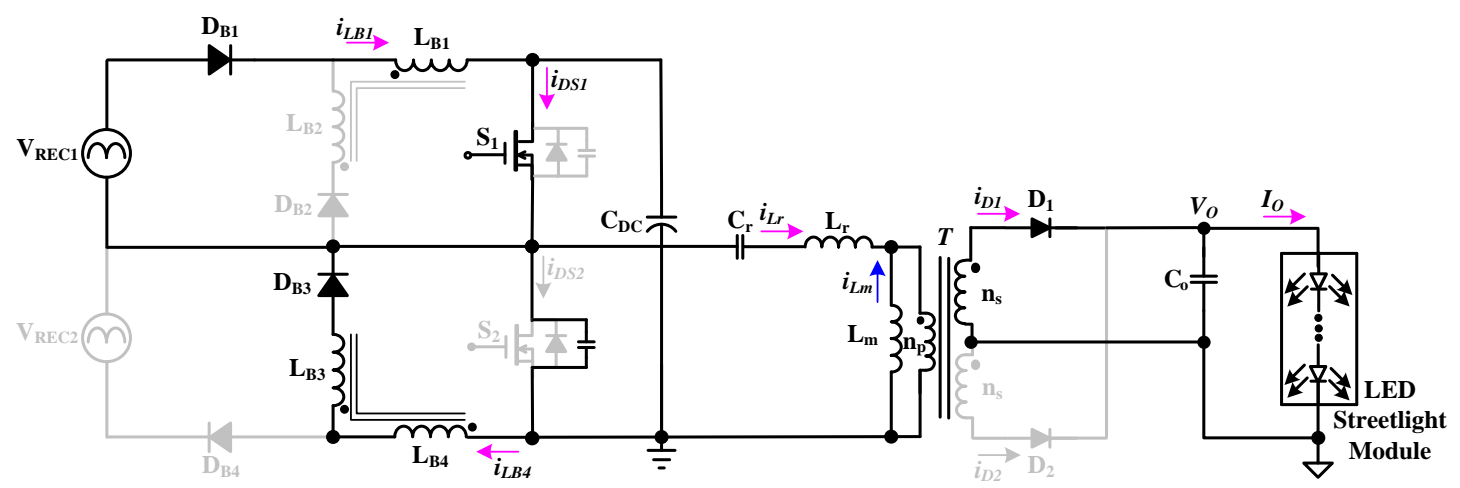

(b) Mode $2\left(t_{1} \leq t<t_{2}\right)$

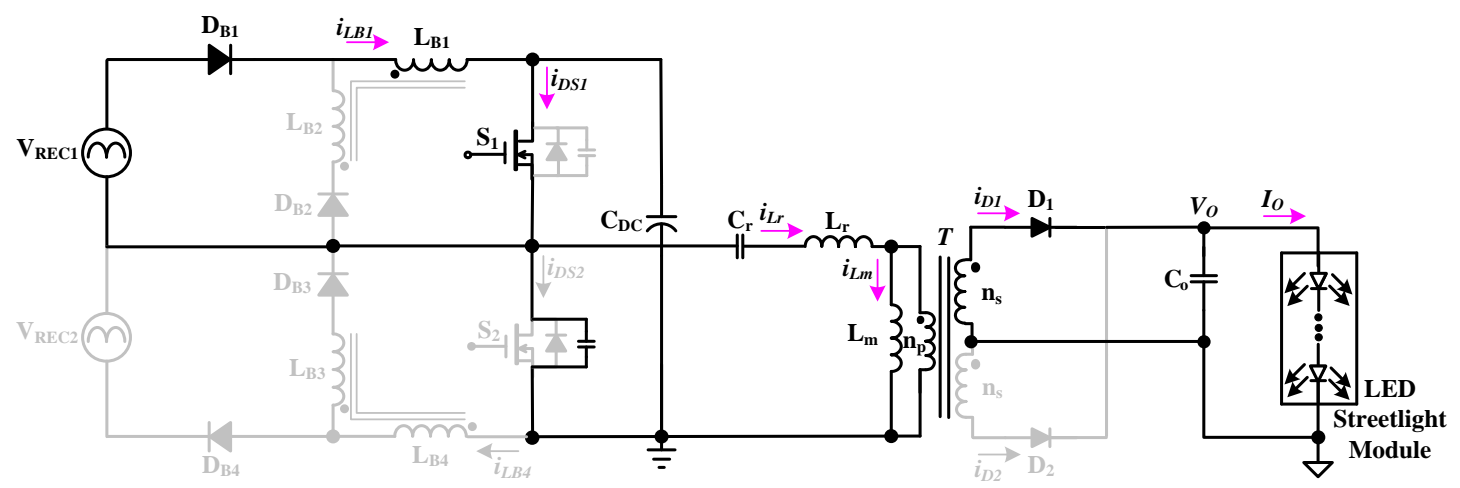

(c) Mode $3\left(t_{2} \leq t<t_{3}\right)$

Figure 4. Cont. 


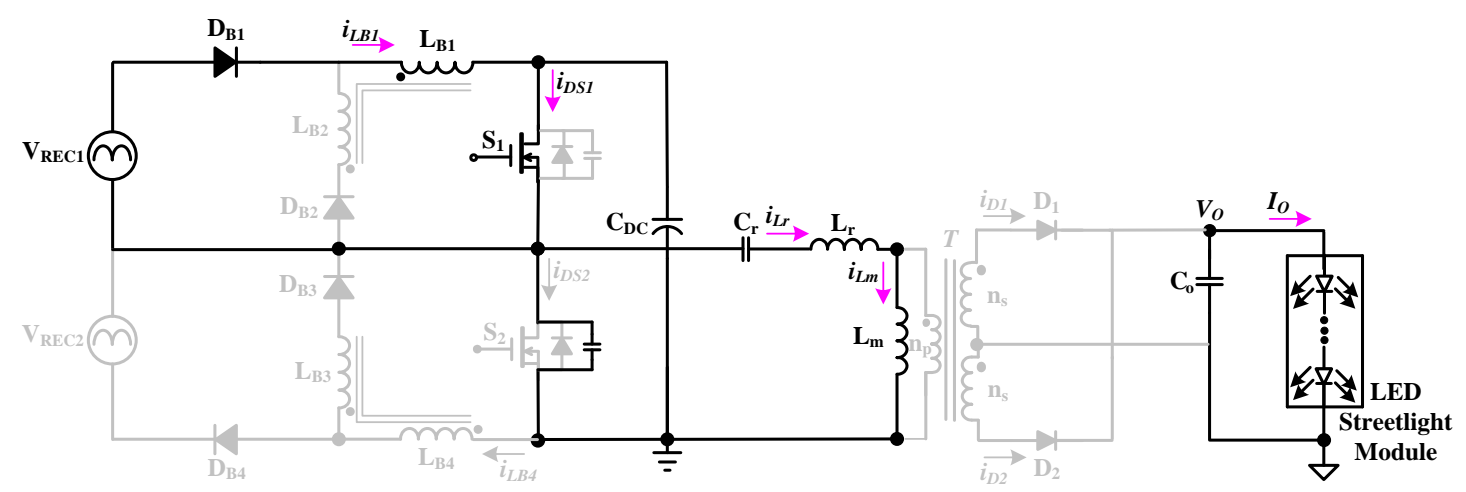

(d) Mode $4\left(t_{3} \leq t<t_{4}\right)$

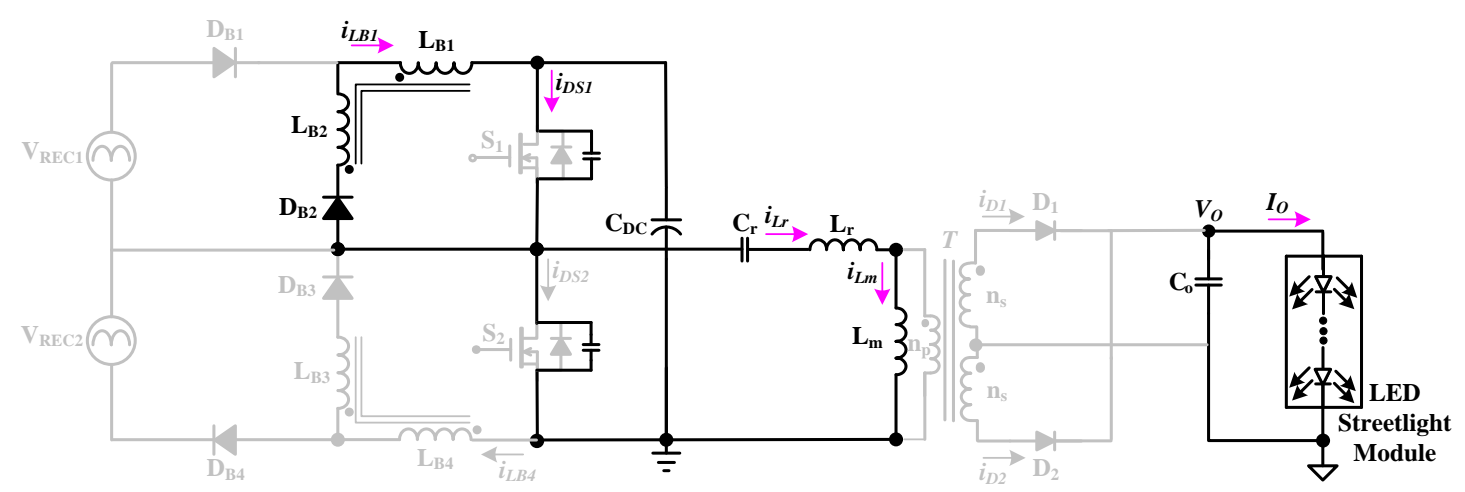

(e) Mode $5\left(t_{4} \leq t<t_{5}\right)$

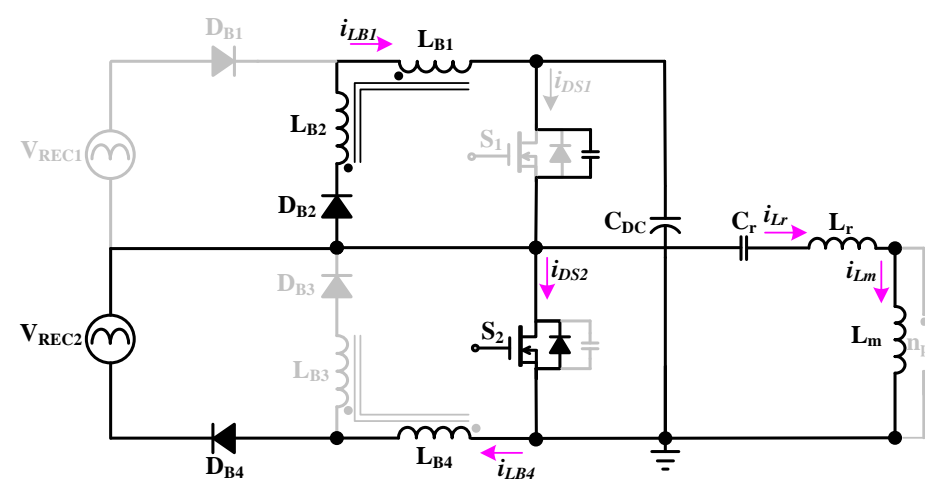

(f) Mode $6\left(t_{5} \leq t<t_{6}\right)$

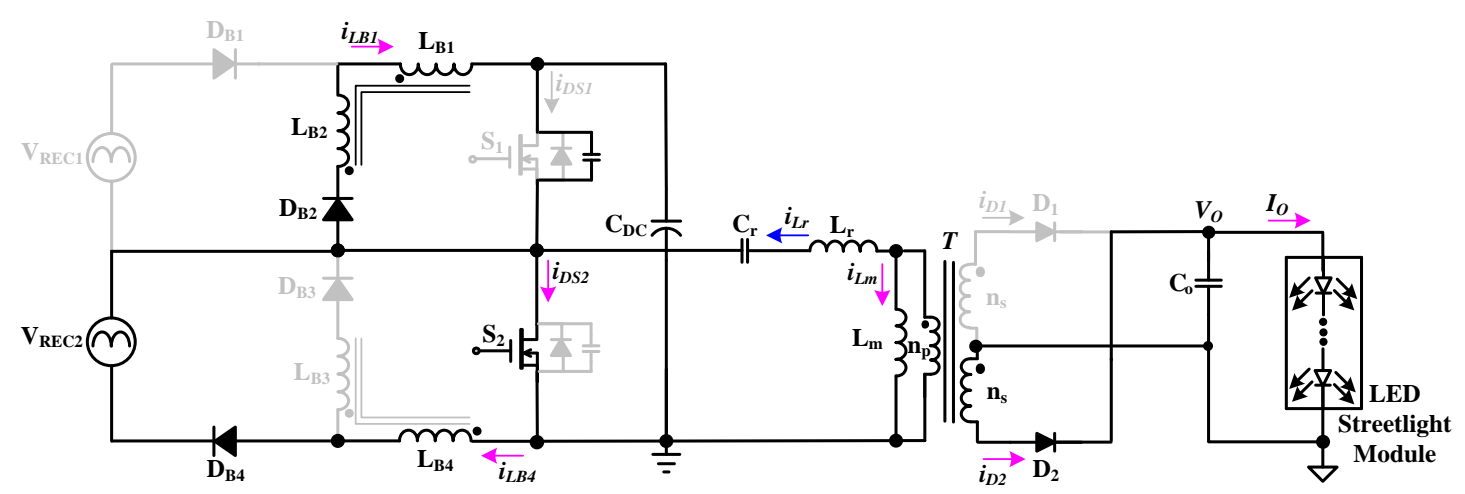

(g) Mode $7\left(t_{6} \leq t<t_{7}\right)$

Figure 4. Cont. 


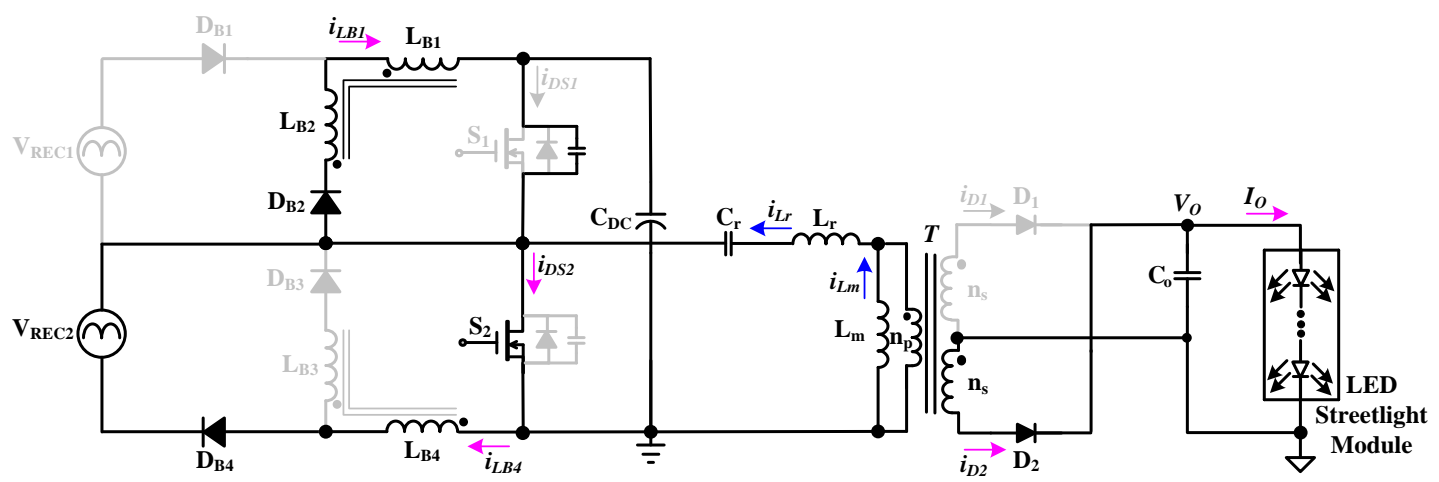

(h) Mode $8(t>t<t<)$

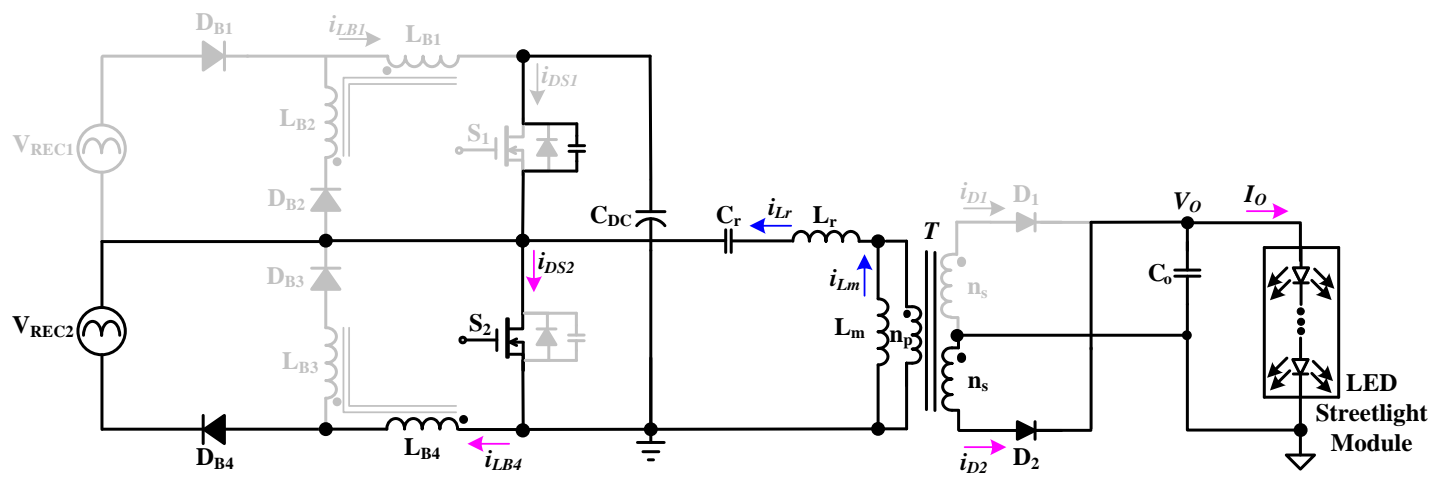

(i) Mode $9\left(t_{8} \leq t<t_{9}\right)$

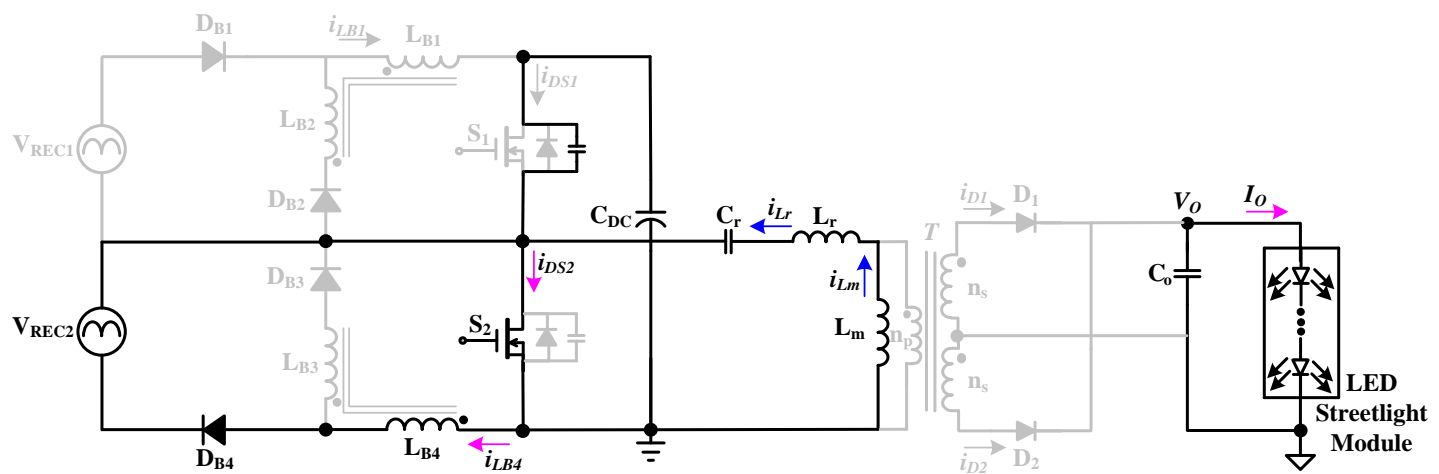

(j) Mode $10\left(t_{9} \leq t<t_{10}\right)$

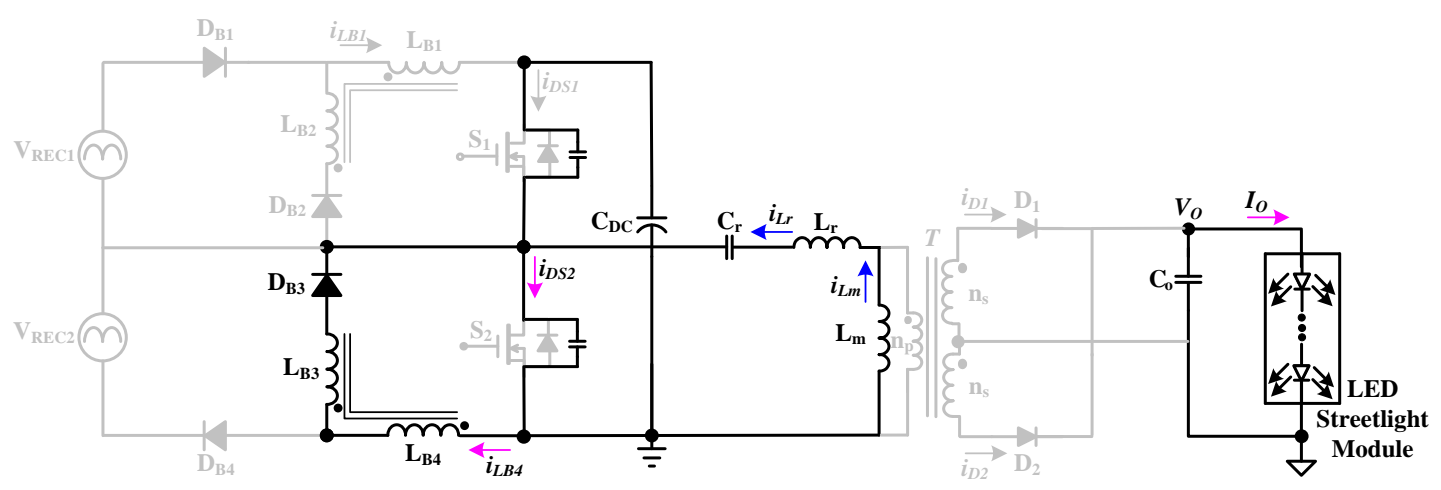

(k) Mode $11\left(t_{10} \leq t<t_{11}\right)$

Figure 4. Operation modes of the presented LED driver. (a) Mode 1; (b) Mode 2; (c) Mode 3; (d) Mode 4; (e) Mode 5; (f) Mode 6; (g) Mode 7; (h) Mode 8; (i) Mode 9; (j) Mode 10; (k) Mode 11. 


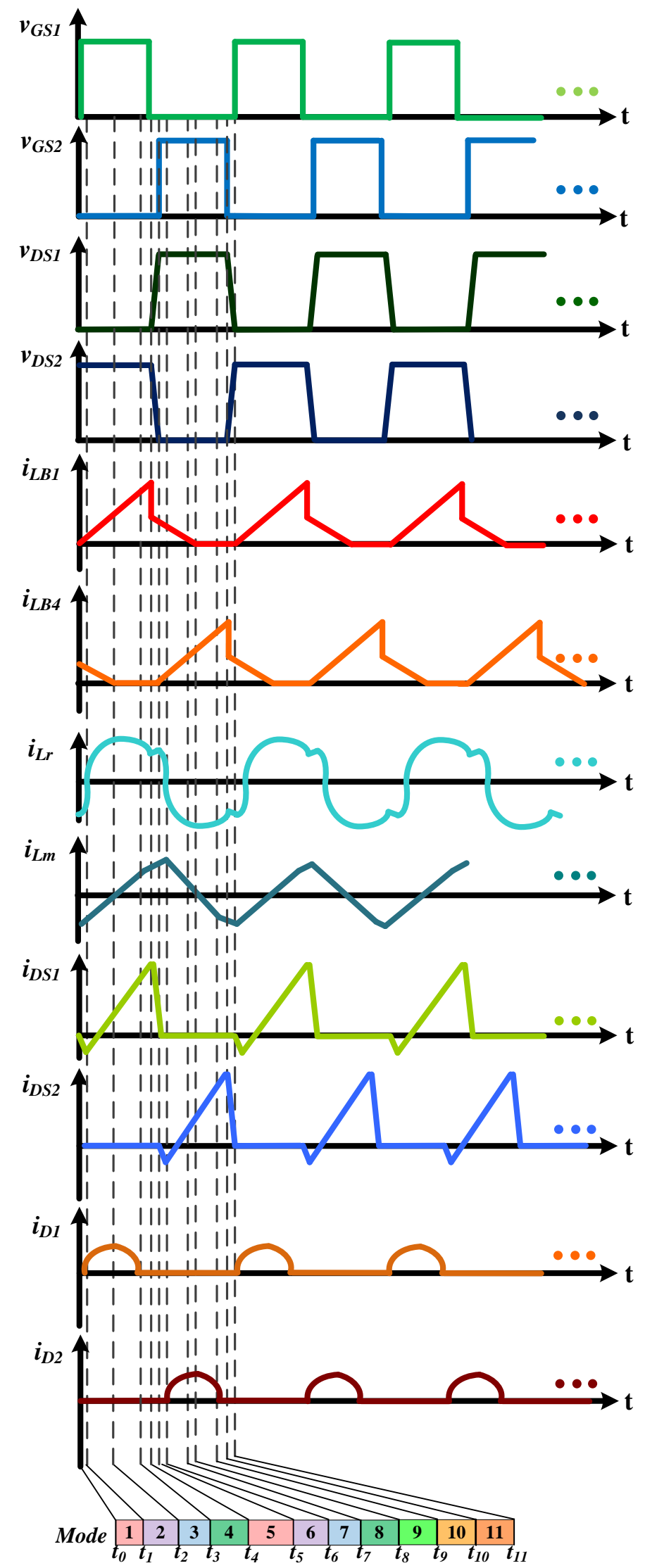

Figure 5. Key waveforms of the presented LED driver for streetlight applications. 


\section{Design Considerations in the Presented LED Streetlight Driver}

\subsection{Design of Coupled Inductors $L_{B 1}, L_{B 2}, L_{B 3}$ and $L_{B 4}$}

Referring to Figure 3, the rectified voltages $V_{R E C 1}$ and $V_{R E C 2}$ are theoretically equal due to the same capacitance of capacitors $C_{i n 1}$ and $C_{i n 2}$, and they can be expressed by

$$
V_{R E C 1}(t)=V_{R E C 2}(t)=\frac{\sqrt{2} v_{A C-r m s}\left|\sin \left(2 \pi f_{A C} t\right)\right|}{2}
$$

The switching frequency $f_{S}$ is much larger than the line frequency $f_{A C}$; thus, rectified voltages $V_{R E C 1}$ and $V_{R E C 2}$ could be regarded as a constant value during one switching period. Referring to Figure $2 \mathbf{b}$, the peak level of diode currents $i_{D B 1}$ and $i_{D B 4}$ can be represented by

$$
i_{D B 1, p k}(t)=i_{D B 4, p k}(t)=\frac{\sqrt{2} v_{A C-r m s}\left|\sin \left(2 \pi f_{A C} t\right)\right| D u t y}{2 L_{B} f_{S}}
$$

where $L_{B}$ represents the inductance of coupled inductors $L_{B 1}, L_{B 2}, L_{B 3}$ and $L_{B 4}$, and Duty is the duty cycle of the switches $S_{1}$ and $S_{2}$.

The peak level of the rectified input current $i_{r e c}$, denoted as $i_{r e c, p k}$, can be represented by

$$
i_{r e c, p k}(t)=i_{D B 1, p k}(t)+i_{D B 4, p k}(t)=\frac{\sqrt{2} v_{A C-r m s}\left|\sin \left(2 \pi f_{A C} t\right)\right| D u t y}{L_{B} f_{s}}
$$

By filtering the high-frequency components of $i_{r e c, p k(t)}$, the input current $i_{A C}$ is equal to the average level of $i_{r e c, p k(t)}$ during one switching period and can be expressed as

$$
i_{A C}(t)=\frac{1}{T_{A C}} \int_{0}^{T_{A C}} i_{r e c, p k}(t) \cdot d t=\frac{\sqrt{2} v_{A C-r m s} D u t y^{2}\left(\sin \left(2 \pi f_{A C} t\right)\right)}{2 L_{B} f_{S}}
$$

where $T_{A C}$ is the utility-line period.

The average value of input utility-line power $P_{\text {in }}$ is obtained by:

$$
P_{i n}=\frac{1}{T_{A C}} \int_{0}^{T_{A C}} v_{A C}(t) i_{A C}(t) d t=\frac{v_{A C-r m s}^{2} D u t y^{2}}{4 L_{B} f_{s}}
$$

The rated output power $P_{o}$ of the LED street-lighting module is related with input power $P_{\text {in }}$ and is given by

$$
P_{o}=\eta P_{\text {in }}
$$

where $\eta$ is the estimated efficiency of the LED driver.

From (8) and (9), the design equation of the inductance $L_{B}$ of coupled inductors is given by

$$
L_{B}=\frac{\eta v_{A C-r m s}^{2} D u t y^{2}}{4 P_{o} f_{S}}
$$

With a $\eta$ of 0.85 , a Duty of 0.5 , a $P_{o}$ of $144 \mathrm{~W}$, a switching frequency $f_{S}$ of $100 \mathrm{kHz}$, and a $v_{A C-r m s}$ of $220 \mathrm{~V}$, the inductance $L_{B}$ of coupled inductors is given by

$$
L_{B}=\frac{0.85 \cdot 220^{2} \cdot 0.5^{2}}{4 \cdot 144 \cdot 100 k}=178.6 \mu \mathrm{H}
$$


3.2. Determining the Transformer Turns-Ratio $n$

The turns-ratio $n$ of transformer $T$ is given as

$$
n=\frac{n_{p}}{n_{s}} \geq \frac{D \sqrt{2} v_{A C-r m s}}{V_{o}+V_{F}}
$$

where $V_{F}$ is the forward voltage drop of the output-rectifier diodes $D_{1}$ and $D_{2}$; and $V_{o}$ is the output voltage.

With a $V_{o}$ of $36 \mathrm{~V}$ and a $V_{F}$ of $0.7 \mathrm{~V}$, the turns-ratio $n$ is given by

$$
n=\frac{n_{p}}{n_{s}} \geq \frac{0.5 \cdot \sqrt{2} \cdot 220}{36+0.7}=4.3
$$

The turns-ratio $n$ is selected as 5 .

\subsection{Determining the LLC Resonant Network}

The quality factor $Q_{r}$ is defined as

$$
Q_{r}=\frac{\sqrt{L_{r}}}{R_{a} \sqrt{C_{r}}}
$$

where $R_{e q}$ is the equivalent output resistor referring to the primary side of transformer $T$, and which can be expressed by the following equation:

$$
R_{e q}=\frac{8 n^{2} V_{o}}{\pi^{2} I_{o}}
$$

The main resonant frequency $\omega_{r 1}$ and secondary resonant frequency $\omega_{r 2}$ of the LLC resonant network are respectively defined as

$$
\begin{gathered}
\omega_{r 1}=2 \pi f_{r 1}=\frac{1}{\sqrt{L_{r} C_{r}}} \\
\omega_{r 2}=2 \pi f_{r 2}=\frac{1}{\sqrt{\left(L_{m}+L_{r}\right) C_{r}}}
\end{gathered}
$$

The inductance ratio $A$ is defined as

$$
A=\frac{L_{m}}{L_{r}}
$$

In addition, substituting (16) into (14) and (15), the secondary resonant frequency $f_{r 2}$ is given by

$$
f_{r 2}=\sqrt{\frac{f_{r 1}{ }^{2}}{A+1}}
$$

With an $f_{r 1}$ of $120 \mathrm{kHz}$ and an $A$ of 5 , the secondary resonant frequency $f_{r 2}$ is computed by

$$
f_{r 2}=\sqrt{\frac{(120 k)^{2}}{5+1}} \cong 49 \mathrm{kHz}
$$

Dividing (12) by (14), the resonant inductor $L_{r}$ can be expressed by

$$
L_{r}=\frac{Q_{r} R_{e q}}{2 \pi f_{r 1}}
$$


The resonant capacitor $C_{r}$ can be obtained by

$$
C_{r}=\frac{1}{\left(2 \pi f_{r 1}\right)^{2} L_{r}}
$$

With an $f_{r 1}$ of $120 \mathrm{kHz}$, an $R_{e q}$ of $182.4 \Omega$, an $A$ of 5 and a $Q_{r}$ of 0.4 , the resonant inductor $L_{r}$ is given by

$$
L_{r}=\frac{Q_{r} R_{e q}}{2 \pi f_{r 1}}=\frac{0.4 \cdot 182.4}{2 \pi \cdot 120 k}=96.8 \mu \mathrm{H}
$$

In addition, the inductor $L_{r}$ is selected as $90 \mu \mathrm{H}$, and the magnetic inductor $L_{m}$ is selected as $450 \mu \mathrm{H}$ according to (16).

The resonant capacitor is given by

$$
C_{r}=\frac{1}{\left(2 \pi f_{r 1}\right)^{2} L_{r}}=\frac{1}{(2 \pi \cdot 120 k)^{2} \cdot 90 \mu}=19.5 n F
$$

Additionally, the resonant capacitor $C_{r}$ is selected as $22 \mathrm{nF}$.

\subsection{Design Guidelines of Achieving Soft-Switching in the Proposed LED Streetlight Driver}

By using the fundamental approximation method, the voltage gain $\left|M_{V}\right|$ of the LLC resonant network is given by [18]:

$$
\begin{aligned}
& \left|M_{V}\left(2 \pi f_{S}\right)\right|=\frac{n \frac{4 V_{O}}{\pi} \sin 2 \pi f_{S} t}{\frac{2}{\pi} V_{D C} \sin 2 \pi f_{S} t}=\frac{2 n \cdot V_{o}}{V_{D C}} \cong \frac{2 n \cdot V_{o}}{\sqrt{2} \cdot v_{A C-r m s}} \\
& =\left|\begin{array}{c}
A\left(\frac{f_{S}}{f_{r 1}}\right)^{2} \\
\mid\left[(A+1)\left(\frac{f_{S}}{f_{r 1}}\right)^{2}-1\right]+j Q_{r} A\left(\frac{f_{S}}{f_{r 1}}\right)\left[\left(\frac{f_{S}}{f_{r 1}}\right)^{2}-1\right]
\end{array}\right|
\end{aligned}
$$

In this design procedure of the proposed LED streetlight driver, the main resonant frequency $f_{r 1}$, the inductance ratio $A$, and quality factor $Q_{r}$ are selected to be $120 \mathrm{kHz}, 5$, and 0.4 , respectively. According to (20), Figure 6 shows the relationship between voltage gain $\left|M_{V}\right|$ and switching frequency $f_{S}$ under different quality factor $Q_{r}$. In addition, the right-hand side and left-hand side of the pink line (which is the constraint line for achieving soft-switching) are inductive region and capacitive region, respectively. To achieve soft-switching for reducing power losses in the proposed LED streetlight driver, the LLC resonant network inside the driver is recommended to be operated at inductive region. Moreover, with a turns-ratio $n$ of 5 , an output voltage $V_{O}$ of $36 \mathrm{~V}$ and a rated input utility-line voltage $v_{A C-r m s}$ of $220 \mathrm{~V}$, the rated voltage gain $M_{V-\text { rated }}$ is obtained by

$$
M_{V-\text { rated }}=\frac{2 n V_{O}}{\sqrt{2} \cdot v_{A C-r m s}}=\frac{2 \cdot 5 \cdot 36}{\sqrt{2} \cdot 220}=1.16
$$

In addition, the switching frequency $f_{S}$ is designed at $100 \mathrm{kHz}$ under a rated voltage gain $M_{V \text {-rated }}$ of 1.16. If the rated input utility-line voltage has some variations (for example, 10V), the required maximum voltage gain $M_{V-\max }$ occurred at minimum input voltage and the required minimum voltage gain $M_{V \text {-min }}$ occurred at maximum input voltage are respectively calculated by

$$
\begin{aligned}
& M_{V-\max }=\frac{2 n V_{O}}{\sqrt{2} \cdot v_{A C-\min }}=\frac{2 \cdot 5 \cdot 36}{\sqrt{2} \cdot(220-10)}=1.21 \\
& M_{V-\min }=\frac{2 n V_{O}}{\sqrt{2} \cdot v_{A C-\max }}=\frac{2 \cdot 5 \cdot 36}{\sqrt{2} \cdot(220+10)}=1.11
\end{aligned}
$$


Please see Figure 6, by using variable frequency control scheme, the switching frequencies under required maximum and minimum voltage gains $\left(M_{V-\max }\right.$ and $\left.M_{V-\min }\right)$ are adjusted to be $90 \mathrm{kHz}$ and $110 \mathrm{kHz}$ due to variations of input utility-line voltage, respectively. Furthermore, these switching frequencies are located at the right-hand side of the pink line. As a result, soft-switching features are also achieved when the rated input utility-line voltage has variations of $10 \mathrm{~V}$.

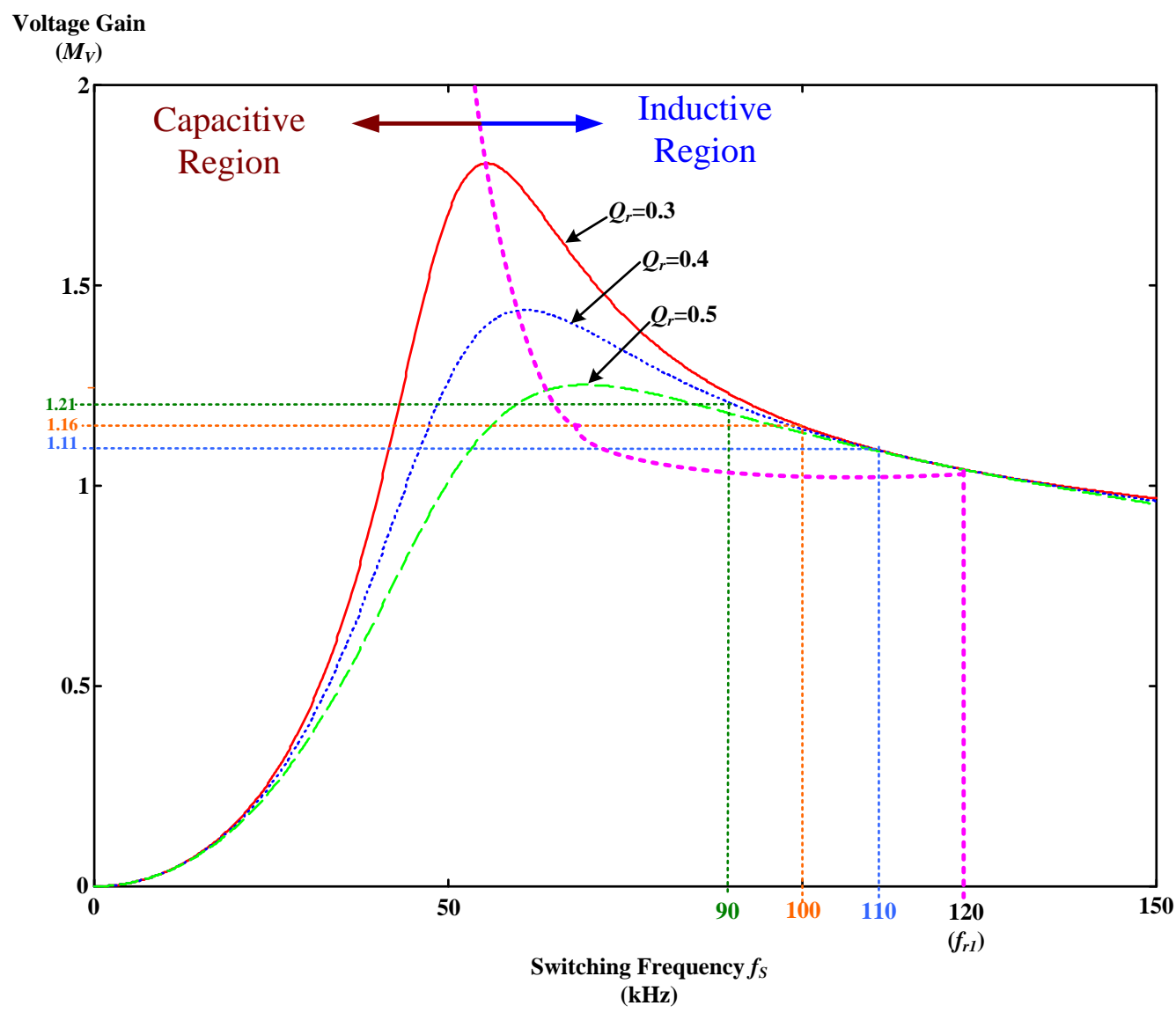

Figure 6. Relationship between the voltage gain $M_{V}$ of LLC resonant tank and the switching frequency $f_{S}$.

\section{Experimental Results of the Prototype LED Streetlight Driver}

A prototype driver has been successfully developed and implemented for supplying a $144 \mathrm{~W}$-rated (36V/4A) LED streetlight module with an input utility-line voltage of $220 \mathrm{~V}$. Tables 1 and 2, respectively, show the specifications and key components utilized in the presented single-stage LED streetlight driver. Additionally, Figure 7 shows the proposed LED streetlight driver with control block diagram. A constant-voltage and constant-current (CV-CC) controller is adopted to sense the output voltage through resistors $R_{V S 1}$ and $R_{V S 2}$, while simultaneously sensing the output current through the resistor $R_{C S}$ for supplying the rated voltage and current to the experimental LED street-lighting module. The output signal of the CV-CC controller feeds into the high-voltage resonant controller through a photo-coupler. Two gate-driving signals $v_{g s 1}$ and $v_{g s 2}$ generating from the resonant controller regulate the output voltage and current of the LED street-lighting module by utilizing variable-frequency control scheme. Moreover, the coupled-inductors $\left(L_{B 1}, L_{B 2}, L_{B 3}\right.$ and $\left.L_{B 4}\right)$ are designed to be operated at discontinuous conduction mode (DCM) for naturally achieving input-current shaping without utilizing a power-factor-correction controller with a feed-forward controlling path. 
Table 1. Specifications of the presented singles-stage LED streetlight driver.

\begin{tabular}{cc}
\hline Parameter & Value \\
\hline Input Utility-Line Voltage $v_{A C}$ & $220 \mathrm{~V}(\mathrm{rms})$ \\
Output Rated Power $P_{O}$ & $144 \mathrm{~W}$ \\
Output Rated Voltage $V_{O}$ & $36 \mathrm{~V}$ \\
Output Rated Current $I_{O}$ & $4 \mathrm{~A}$ \\
\hline
\end{tabular}

Table 2. Key components utilized in the presented LED streetlight driver.

\begin{tabular}{cc}
\hline Component & Value \\
\hline Capacitors $C_{i n 1}, C_{i n 2}$ & $330 \mathrm{nF}$ \\
Inductors $L_{B 1}, L_{B 2}, L_{B 3}, L_{B 4}$ & $179 \mu \mathrm{H}$ \\
Diodes $D_{B 1}, D_{B 2}, D_{B 3}, D_{B 4}$ & MUR460 \\
Power Switches $S_{1}, S_{2}$ & STP20NM60 \\
DC-Linked Capacitor $C_{D C}$ & $220 \mu \mathrm{F} / 450 \mathrm{~V}$ \\
Magnetizing Inductor $L_{m}$ & $450 \mu \mathrm{H}$ \\
Resonant Inductor $L_{r}$ & $90 \mu \mathrm{H}$ \\
Resonant Capacitor $C_{r}$ & $22 \mathrm{nF}$ \\
Diodes $D_{1}, D_{2}$ & MBR30H100CT \\
Output Capacitor $C_{o}$ & $2200 \mu \mathrm{F} / 63 \mathrm{~V}$ \\
Filter Inductor $L_{f}$ & $2.5 \mathrm{mH}$ \\
Filter Capacitor $C_{f}$ & $1 \mu \mathrm{F}$ \\
\hline
\end{tabular}

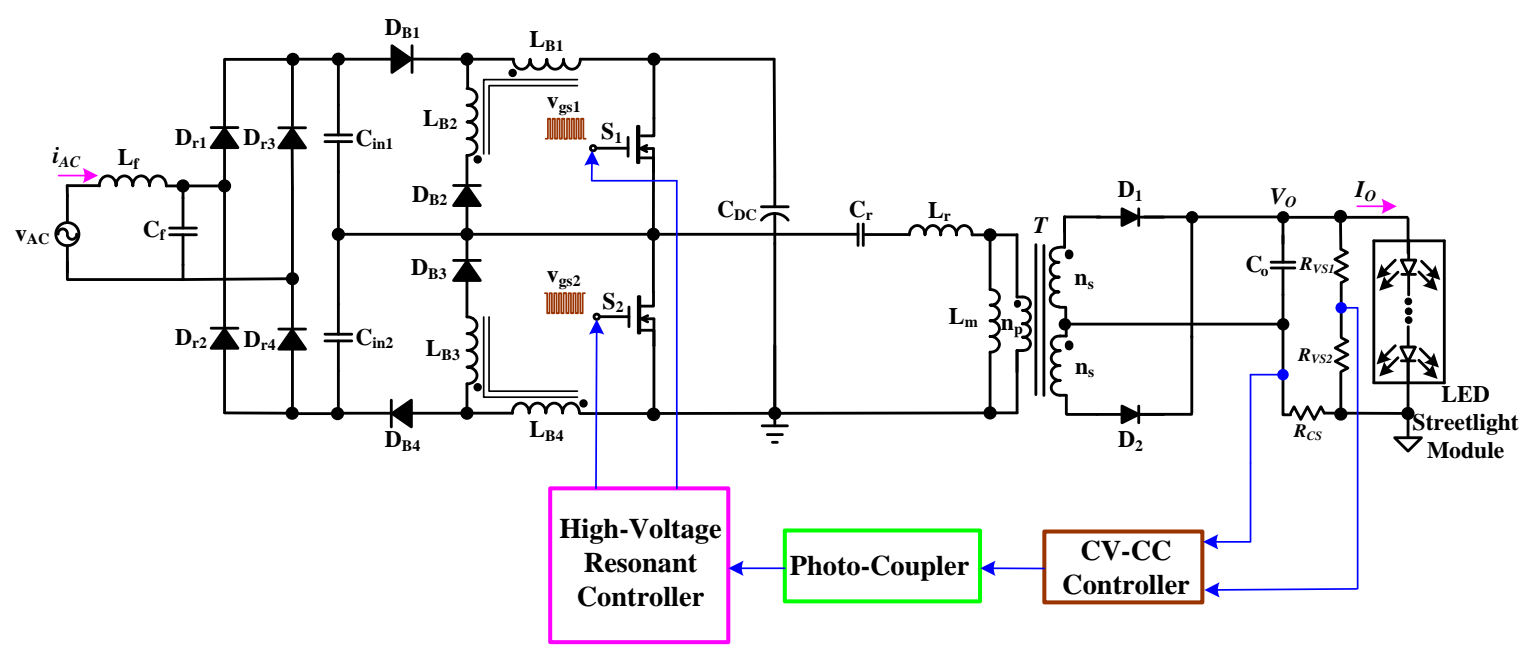

Figure 7. The proposed LED streetlight driver with control block diagram.

The measured waveforms of coupled-inductor currents $i_{L B 1}$ and $i_{L B 4}$ are shown in Figure 8; both have interleaved features and operate in DCM. Figure 9 shows the measured switch voltage $v_{D S 2}$ and switch current $i_{D S 2}$; thus, ZVS has occurred on the power switch for lowering switching losses. Figure 10 presents the measured switch voltage $v_{D S 2}$ and resonant inductor current $i_{L r}$. Figure 11 presents the measured switch voltage $v_{D S 2}$ and current $i_{D 2}$ of the output rectified diode $D_{2} ;$ thus, ZCS has occurred on the power diode for decreasing the conduction losses. Figure 12 depicts the measured output voltage $V_{O}$ and current $I_{O}$; their average values are approximately $36 \mathrm{~V}$ and $4 \mathrm{~A}$, respectively. 


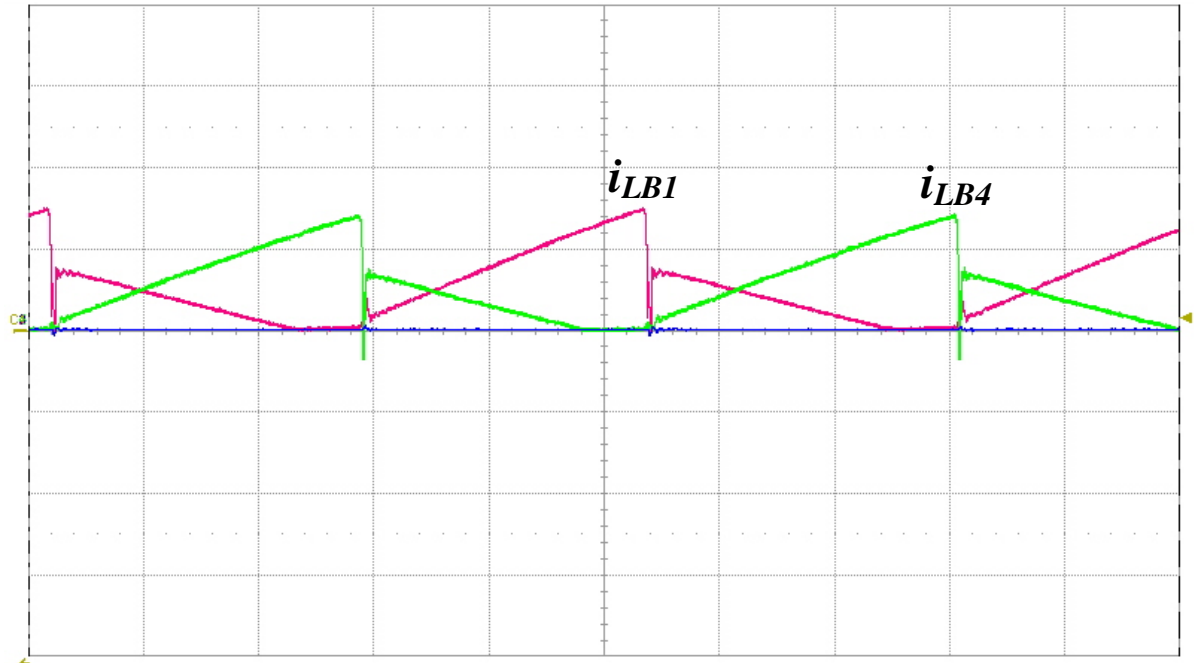

Figure 8. Measured currents $i_{L B 1}(2 \mathrm{~A} / \mathrm{div})$ and $i_{L B 4}(2 \mathrm{~A} / \mathrm{div})$ of the coupled inductors; time scale: $2 \mu \mathrm{s} / \mathrm{div}$.

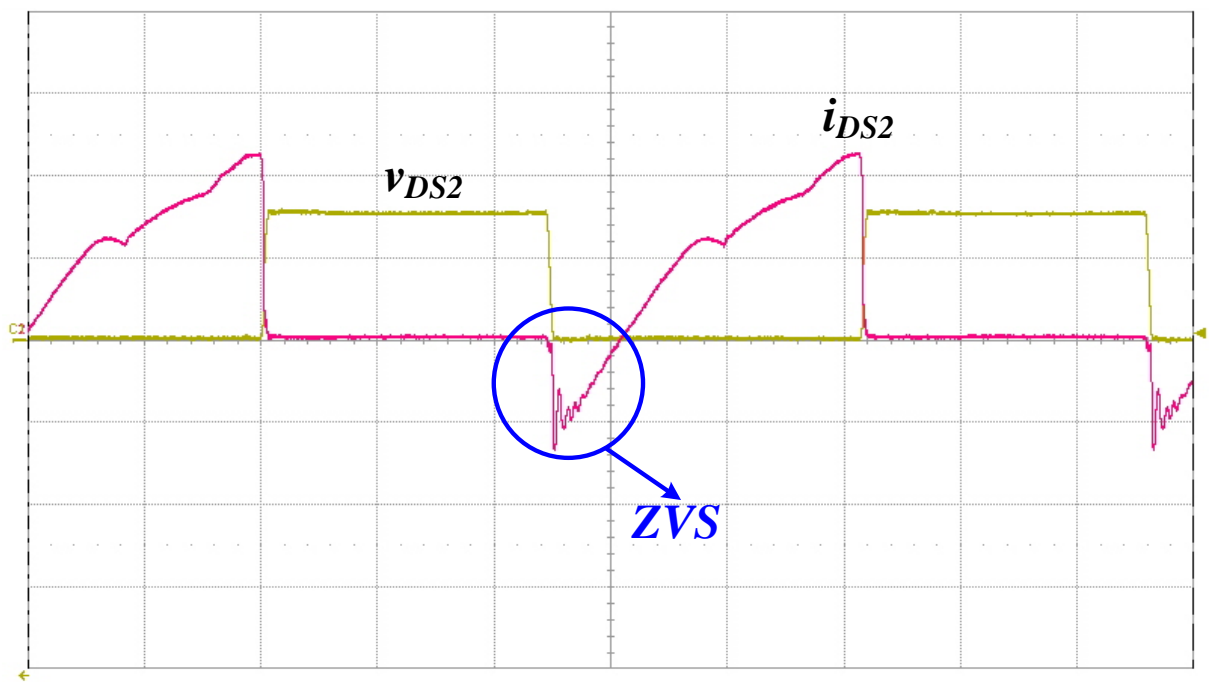

Figure 9. Measured switch voltage $v_{D S 2}(200 \mathrm{~V} / \mathrm{div})$ and current $i_{D S 2}(2 \mathrm{~A} / \mathrm{div}) ;$ time scale: $2 \mu \mathrm{s} / \mathrm{div}$.

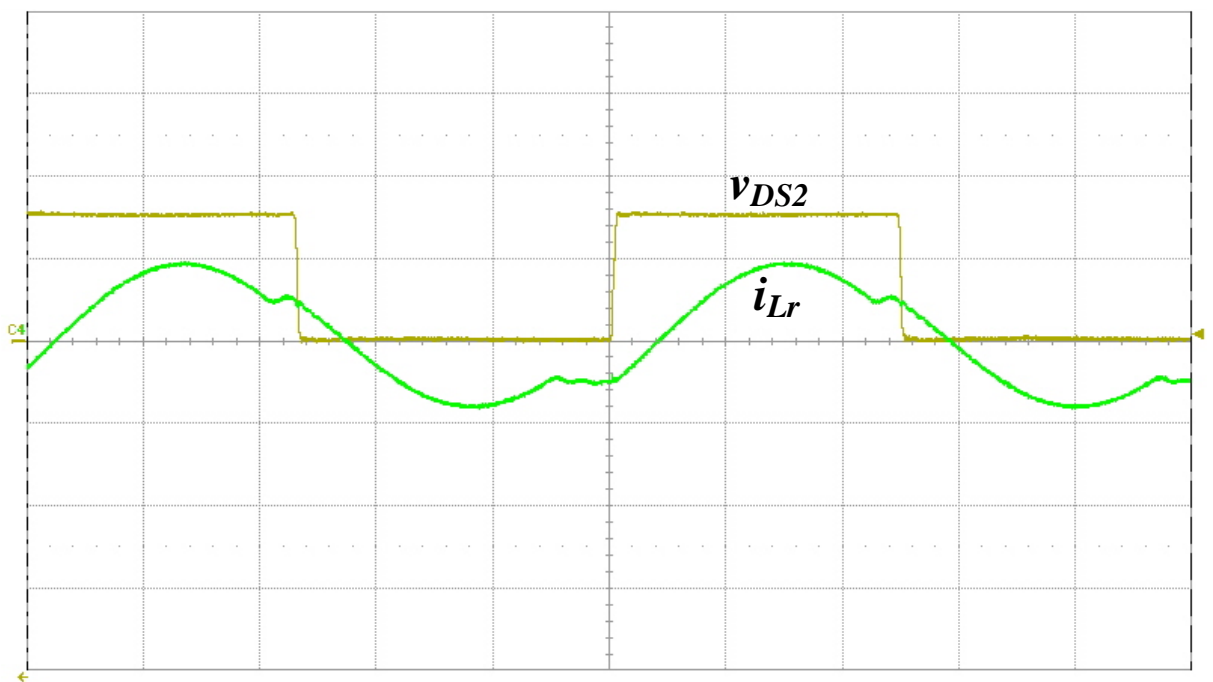

Figure 10. Measured switch voltage $v_{D S 2}(200 \mathrm{~V} / \mathrm{div})$ and current $i_{L r}(2 \mathrm{~A} / \mathrm{div})$; time scale: $2 \mu \mathrm{s} / \mathrm{div}$. 


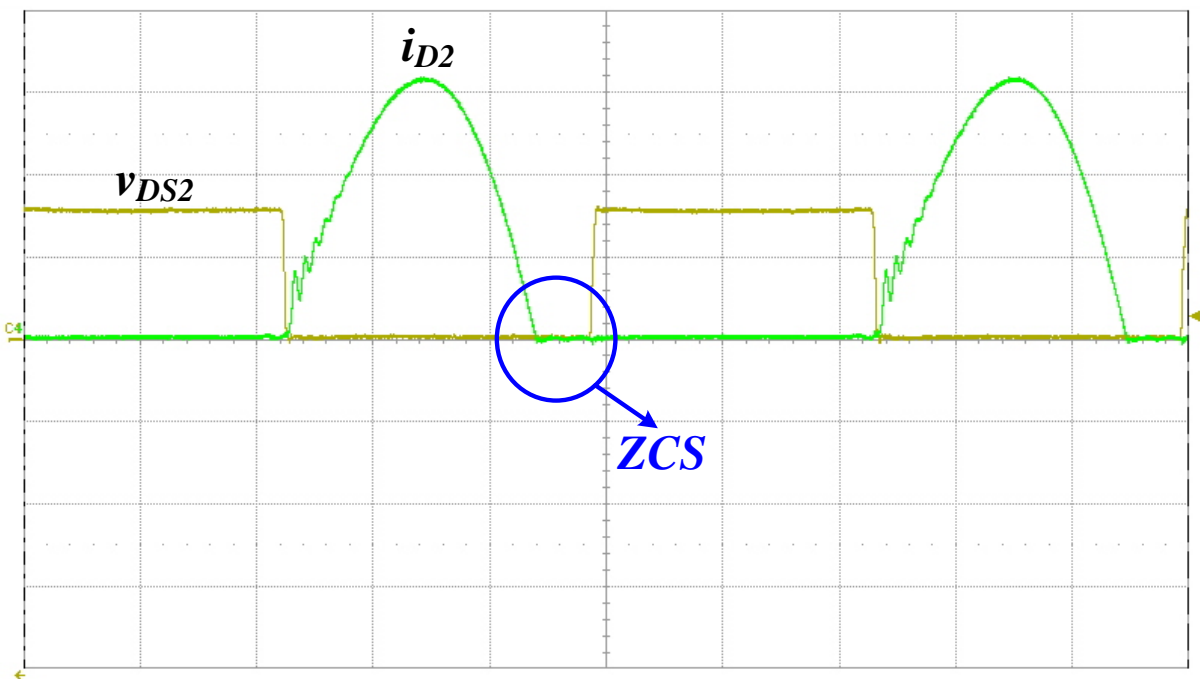

Figure 11. Measured switch voltage $v_{D S 2}(200 \mathrm{~V} / \mathrm{div})$ and current $i_{D 2}(2 \mathrm{~A} / \mathrm{div})$ of the output rectified diode $D_{4}$; time scale: $2 \mu \mathrm{s} /$ div.

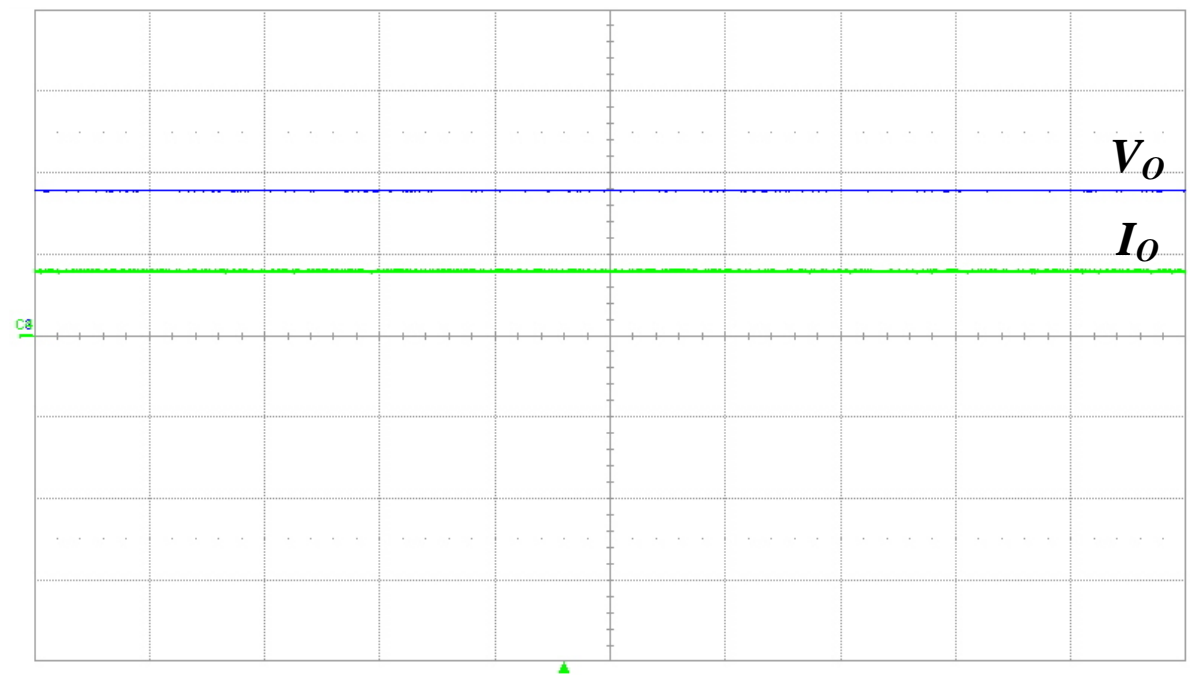

Figure 12. Measured output voltage $V_{O}(20 \mathrm{~V} / \mathrm{div})$ and current $I_{O}(5 \mathrm{~A} / \mathrm{div})$; time scale: $5 \mathrm{~ms} / \mathrm{div}$.

The measured waveforms of input utility-line voltage $v_{A C}$ and current $i_{A C}$ are shown in Figure 13, and the input current is in phase with utility-line voltage, which results in high power factor. In addition, the measured power factor and the circuit efficiency are 0.9684 and $89.69 \%$, respectively, as measured by a power analyzer (Tektronix PA 4000). Figure 14 shows the measured input utility-line current harmonics at an input utility-line voltage of $220 \mathrm{~V}$ in comparison with the International Electrotechnical Commission (IEC) 61000-3-2 Class C standards; all utility-line current harmonics meet the requirements. 


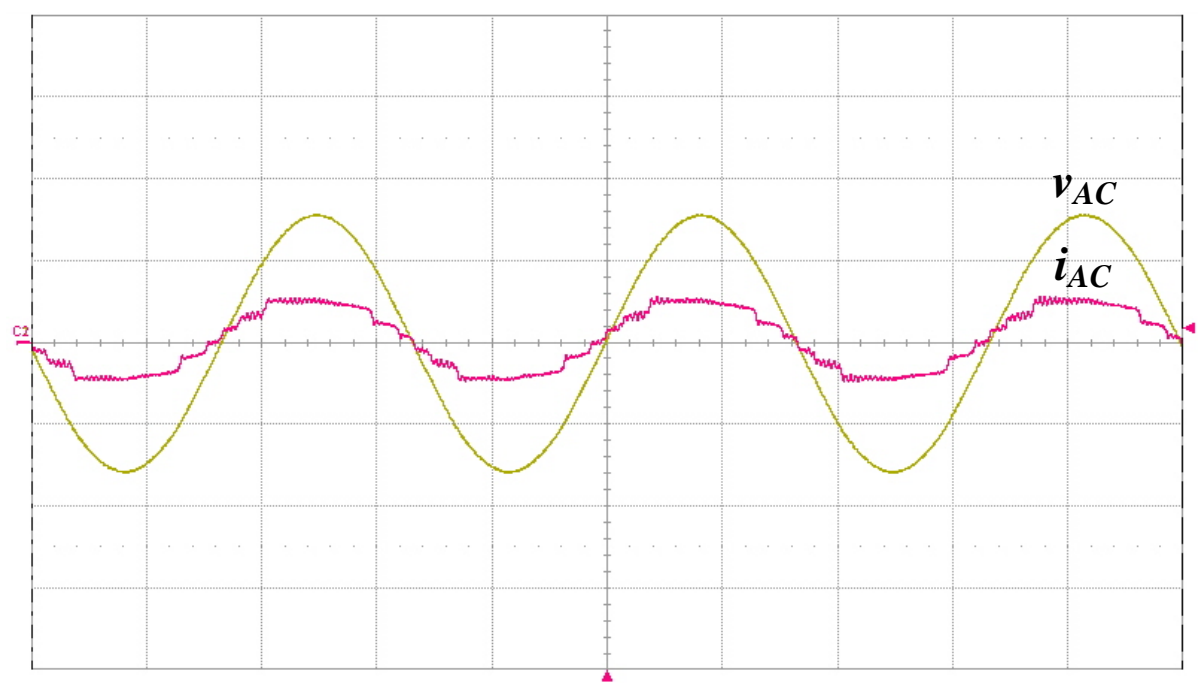

Figure 13. Measured input utility-line voltage $v_{A C}(200 \mathrm{~V} / \mathrm{div})$ and current $i_{A C}(2 \mathrm{~A} / \mathrm{div})$; time scale: $5 \mathrm{~ms} /$ div.

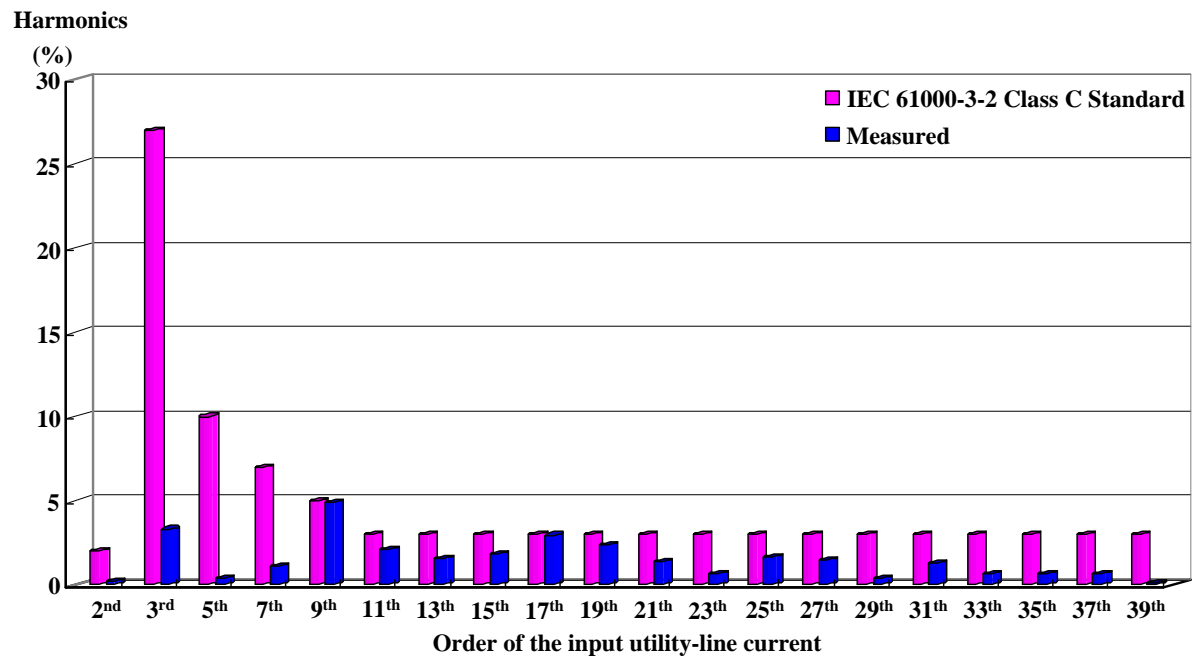

Figure 14. Measured input current harmonics compared with the IEC 61000-3-2 Class C standards.

Table 3 shows the measured output voltage ripple and current ripple of the presented LED streetlight driver at a utility-line voltage of $220 \mathrm{~V}$; additionally, the output voltage (current) ripple factor is obtained by the peak-to-peak level divided by the mean value of output voltage (current). It can be seen that the measured voltage and current ripple factors are smaller than $5 \%$ and $2 \%$, respectively. Figure 15 presents a photo of supplying the LED streetlight module with the proposed streetlight driver at an input utility-line voltage of $220 \mathrm{~V}$. In addition, Table 4 shows comparisons between the existing single-stage LED streetlight driver in references [16-19] and the one proposed in this paper. According to this table, the proposed single-stage LED streetlight driver has a beneficial feature of reduced voltage stress of power switches, which is favorable for operating with high utility-line voltages, in comparison to the existing single-stage versions in the references [16-19]. In addition, the proposed circuit has the lowest current ripple factor among these LED streetlight drivers. 
Table 3. Measured output voltage ripple and current ripple of the presented LED streetlight driver at a utility line voltage of $220 \mathrm{~V}$.

\begin{tabular}{cc}
\hline Parameter & Value \\
\hline Mean Value of Output Voltage $V_{O}$ & $35.85 \mathrm{~V}$ \\
Peak-to-Peak Value of Output Voltage $V_{O}$ & $1.53 \mathrm{~V}$ \\
Voltage Ripple Factor & $4.28 \%$ \\
Mean Value of Output Current $I_{O}$ & $3.95 \mathrm{~A}$ \\
Peak-to-Peak Value of Output Current $I_{O}$ & $48.9 \mathrm{~mA}$ \\
Current Ripple Factor & $1.24 \%$ \\
\hline
\end{tabular}

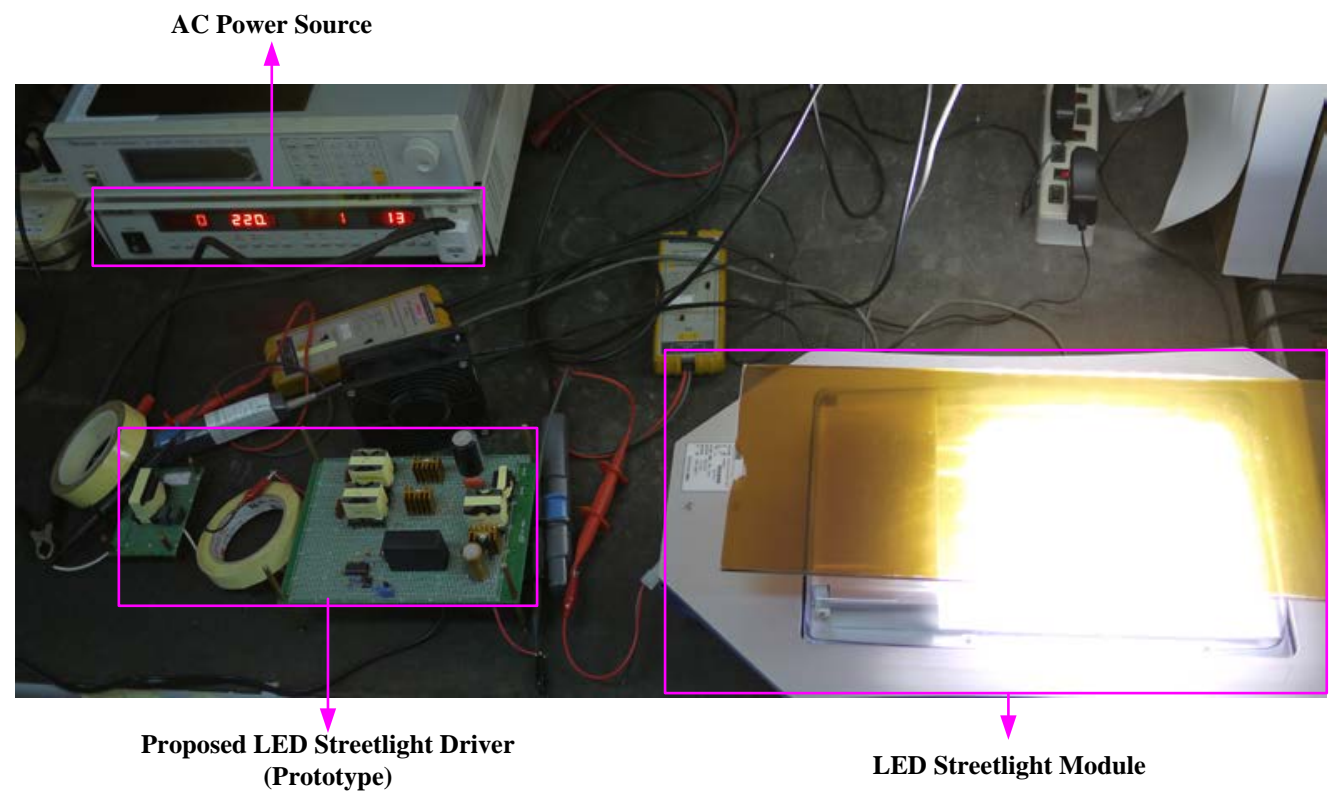

Figure 15. Photo of supplying the LED streetlight module with the proposed streetlight driver at a input utility-line voltage of $220 \mathrm{~V}$. 
Table 4. Comparisons between the existing single-stage LED streetlight driver in [16-19], and the version proposed in this paper.

\begin{tabular}{|c|c|c|c|c|c|}
\hline Item & $\begin{array}{l}\text { Presented Driver } \\
\text { in Reference [16] }\end{array}$ & $\begin{array}{l}\text { Presented Driver } \\
\text { in Reference [17] }\end{array}$ & $\begin{array}{l}\text { Presented Driver } \\
\text { in Reference [18] }\end{array}$ & $\begin{array}{l}\text { Presented Driver } \\
\text { in Reference [19] }\end{array}$ & Proposed Driver \\
\hline Circuit Topology & $\begin{array}{l}\text { Integration of interleaved boost } \\
\text { PFC converter and LLC } \\
\text { resonant converter }\end{array}$ & $\begin{array}{l}\text { Integration of dual buck-boost } \\
\text { converter with coupled inductors } \\
\text { and LLC resonant converter }\end{array}$ & $\begin{array}{l}\text { Integration of modified } \\
\text { bridgeless boost PFC converter } \\
\text { and LLC resonant converter }\end{array}$ & $\begin{array}{l}\text { Integration of dual boost } \\
\text { converter with coupled inductors } \\
\text { and LLC resonant converter }\end{array}$ & $\begin{array}{l}\text { Integration of interleaved } \\
\text { buck-boost converter with } \\
\text { coupled inductors and LLC } \\
\text { resonant converter }\end{array}$ \\
\hline Number of Required Power Switches & 2 & 2 & 2 & 2 & 2 \\
\hline Number of Required Diodes & 8 & 6 & 4 & 4 & 10 \\
\hline & 6 & 5 & 4 & 4 & \\
\hline Number of Required Capacitors & (Including one DC-bus capacitor) & (Including two DC-bus capacitors) & (Including one DC-bus capacitor) & (Including one DC-bus capacitor) & (Including one DC-bus capacitor \\
\hline Number of Required Magnetic Components & 5 & 4 & 4 & 4 & 5 \\
\hline $\begin{array}{l}\text { Input Utility-Line Voltage } \\
\text {. }\end{array}$ & $110 \mathrm{~V}$ & $110 \mathrm{~V}$ & $110 \mathrm{~V}$ & $110 \mathrm{~V}$ & $220 \mathrm{~V}$ \\
\hline Output Power & $144 \mathrm{~W}(36 \mathrm{~V} / 4 \mathrm{~A})$ & $144 \mathrm{~W}(36 \mathrm{~V} / 4 \mathrm{~A})$ & $144 \mathrm{~W}(36 \mathrm{~V} / 4 \mathrm{~A})$ & $144 \mathrm{~W}(36 \mathrm{~V} / 4 \mathrm{~A})$ & $144 \mathrm{~W}(36 \mathrm{~V} / 4 \mathrm{~A})$ \\
\hline Voltage Stress of Power Switches & $\frac{1}{1-D} \sqrt{2} v_{A C-r m s}$ & $\frac{2 D}{1-D} \sqrt{2} v_{A C-r m s}$ & $\frac{1}{1-D} \sqrt{2} v_{A C-r m s}$ & $\frac{1}{1-D} \sqrt{2} v_{A C-r m s}$ & $\frac{D}{1-D} \sqrt{2} v_{A C-r m s}$ \\
\hline Voltage Ripple Factor & $\begin{array}{l}{ }^{1-D}<6 \% \\
<6 \% \text { rms }\end{array}$ & $\begin{array}{l}1-D<>0 \\
<7 \% \text { rms }\end{array}$ & ${ }^{1-D}<8 \%$ & ${ }^{1-D}<4 \%$ & $\begin{array}{l}1-D<5 \% \\
<5 \% \text {-rms }\end{array}$ \\
\hline Current Ripple Factor & $<10 \%$ & $<5 \%$ & $<13 \%$ & $<4 \%$ & $<2 \%$ \\
\hline Measured Power Factor & $>0.99$ & $>0.99$ & $>0.99$ & $>0.98$ & $>0.97$ \\
\hline Measured Circuit Efficiency & $>88 \%$ & $>90 \%$ & $>92 \%$ & $>92 \%$ & $\fallingdotseq 90 \%$ \\
\hline
\end{tabular}




\section{Conclusions}

This paper has presented and implemented a single-stage LED streetlight driver with soft-switching and PFC features; the proposed circuit integrates an interleaved buck-boost converter with coupled inductors and a half-bridge LLC resonant converter into a single power-conversion stage, and is suitable for operating at high utility-line voltages with reduced voltage stress on the DC-linked capacitor. A $144 \mathrm{~W}$ prototype LED driver has been developed and tested with an input utility-line voltage of $220 \mathrm{~V}$. The experimental results of the presented LED streetlight driver display low output-voltage ripple factor $(<5 \%)$, low output-current ripple factor $(<2 \%)$, high power factor $(>0.97)$, ZVS on power switches, ZCS on output rectified diodes, and high circuit efficiency (approximately $90 \%$ ); thus the functionality of the presented LED streetlight driver is validated.

Author Contributions: C.-A.C. and C.-H.C. conceived and designed the circuit. H.-L.C. and E.-C.C. performed circuit simulations. T.-Y.C. and M.-T.C. carried out the prototype driver, and measured as well as analyzed experimental results with the guidance from C.-A.C. E.-C.C. revised the manuscript for submission.

Funding: This research was funded by the Ministry of Science and Technology (MOST) of Taiwan, R.O.C., under its grant with reference number MOST 105-2221-E-214-028.

Acknowledgments: The authors would like to convey their appreciation for grant support from the Ministry of Science and Technology (MOST) of Taiwan, R.O.C., under its grant with reference number MOST 105-2221-E-214-028.

Conflicts of Interest: The authors declare no conflict of interest.

\section{References}

1. Schubert, E.F. Light-Emitting Diodes; Cambridge University Press: New York, NY, USA, 2006.

2. Bender, V.C.; Marchesan, T.B.; Alonso, J.M. Solid-state lighting: A concise review of the state of the art on LED and OLED modeling. IEEE Ind. Electron. Mag. 2015, 9, 6-16. [CrossRef]

3. Almeida, P.S.; Camponogara, D.; Braga, H.; Dalla Costa, M.A.; Alonso, J.M. Matching LED and driver life spans: A review of different techniques. IEEE Ind. Electron. Mag. 2015, 9, 36-47. [CrossRef]

4. $\quad$ Liang, T.J.; Tseng, W.J.; Chen, J.F.; Wu, J.P. A novel line frequency multistage conduction LED driver with high power factor. IEEE Trans. Power Electron. 2015, 30, 5103-5115. [CrossRef]

5. Lee, S.W.; Choe, H.J.; Yun, J.J. Performance improvement of a boost LED driver with high voltage gain for edge-lit LED backlights. IEEE Trans. Circuits Syst. II Express Briefs 2018, 65, 481-485. [CrossRef]

6. Kuo, T.H.; Liang, T.J.; Wu, W.J. Design and implementation of a LED driver with current balancing. In Proceedings of the IEEE 8th International Power Electronics and Motion Control Conference (IPEM-ECCE Asia), Hefei, China, 22-26 May 2016; pp. 3306-3313.

7. Cheng, H.L.; Lin, C.W. Design and implementation of a high power-factor LED driver with zero-voltage switching-on characteristics. IEEE Trans. Power Electron. 2014, 29, 4949-4958. [CrossRef]

8. Wang, Y.; Zhang, S.; Alonso, J.M.; Liu, X.; Xu, D. A single-stage LED driver with high-performance primary-side-regulated characteristic. IEEE Trans. Circuits Syst. II Express Briefs 2018, 65, 76-80. [CrossRef]

9. Alonso, J.M.; Perdigão, M.S.; Abdelmessih, G.Z.; Dalla Costa, M.A.; Wang, Y. SPICE modeling of variable inductors and its application to single inductor LED driver design. IEEE Trans. Ind. Electron. 2017, 64, 5894-5903. [CrossRef]

10. Wang, Y.; Guan, Y.; Xu, D.; Wang, W. A CLCL resonant DC/DC converter for two-stage LED driver system. IEEE Trans. Ind. Electron. 2016, 63, 2883-2891. [CrossRef]

11. Luo, Q.; Huang, J.; He, Q.; Ma, K.; Zhou, L. Analysis and design of a single-stage isolated AC-DC LED driver with a voltage doubler rectifier. IEEE Trans. Ind. Electron. 2017, 64, 5807-5817. [CrossRef]

12. Camponogara, D.; Ferreira, G.F.; Campos, A.; Dalla Costa, M.A.; Garcia, J. Offline LED driver for street lighting with an optimized cascade structure. IEEE Trans. Ind. Appl. 2013, 49, 2437-2443. [CrossRef]

13. Arias, M.; Lamar, D.G.; Sebastian, J.; Balocco, D.; Diallo, A. High-efficiency LED driver without electrolytic capacitor for street lighting. IEEE Trans. Ind. Appl. 2013, 49, 127-137. [CrossRef]

14. Arias, M.; Lamar, D.G.; Linera, F.F.; Balocco, D.; Diallo, A.A.; Sebastian, J. Design of a soft-switching asymmetrical half-bridge converter as second stage of an LED driver for street lighting application. IEEE Trans. Power Electron. 2012, 27, 1608-1621. [CrossRef] 
15. Wang, Y.; Guan, Y.; Liang, X.; Wang, W.; Xu, D. Two-stage LED street lighting system based on a novel single-stage AC/DC converter. IET Power Electron. 2014, 7, 1374-1383. [CrossRef]

16. Cheng, C.A.; Cheng, H.L.; Chang, C.H.; Yang, F.L.; Chung, T.Y. A single-stage LED driver for street-lighting applications with interleaving PFC feature. In Proceedings of the IEEE 2nd International Symposium on Next-Generation Electronics, Kaohsiung, Taiwan, 25-26 February 2013; pp. 150-152.

17. Cheng, C.A.; Cheng, H.L.; Chung, T.Y. A novel single-stage high-power-factor LED street-lighting driver with coupled inductors. IEEE Trans. Ind. Appl. 2014, 50, 3037-3045. [CrossRef]

18. Cheng, C.A.; Chang, C.H.; Chung, T.Y.; Yang, F.L. Design and implementation of a single-stage driver for supplying an LED street-lighting module with power factor corrections. IEEE Trans. Power Electron. 2015, 30, 956-966. [CrossRef]

19. Cheng, C.A.; Chung, T.Y. A single-stage LED streetlight driver with PFC and digital-PWM-dimming capability. Int. J. Circuit Theory Appl. 2016, 44, 1942-1958. [CrossRef]

20. Cheng, C.A.; Tseng, C.H.; Feng, P.H.; Tseng, K.C. A novel single-stage LED driver for energy-saving streetlight applications with interleaved power-factorcorrection. Int. J. Green Energy 2018, 15, 286-295. [CrossRef]

(C) 2019 by the authors. Licensee MDPI, Basel, Switzerland. This article is an open access article distributed under the terms and conditions of the Creative Commons Attribution (CC BY) license (http://creativecommons.org/licenses/by/4.0/). 